\title{
Sustainable energy opportunities in localised food production and transportation: a case study of bread in the UK
}

\author{
Alma López-Avilés a , Anton Johannes Veldhuis ${ }^{b}$, Matthew Leach a , Aidong Yang ${ }^{b}$ \\ a Centre for Environment and Sustainability, University of Surrey, Guildford GU2 7XH, \\ United Kingdom
}

A. López-Avilés (corresponding author)
e-mail: a.lopez-aviles@surrey.ac.uk; almalopezaviles@gmail.com

M. Leach

e-mail: m.leach@surrey.ac.uk

b Department of Engineering Science, University of Oxford, Parks Road, Oxford, OX1 3PJ, United Kingdom

\author{
A.J. Veldhuis \\ e-mail: a.j.veldhuis@outlook.com
}

A. Yang

e-mail: aidong.yang@eng.ox.ac.uk

\begin{abstract}
Re-distributed manufacturing (RDM) is of high economic and political interest and is associated with rapid technological, environmental, political, regulatory and social changes in the UK. RDM of food raises opportunities and questions around the local nexus of food, energy and water. Considering these together can provide opportunities for rationalising resource utilisation, production, and consumption while contributing to shared prosperity between business, society and natural ecosystems. This paper concentrates on the energy-food aspects of the nexus for RDM by focusing on the case study of bread manufacturing and transportation in the UK. A detailed analysis of the energy requirements and environmental impacts of centralised bread production and transportation compared with localised options for re-distributed bread manufacturing is undertaken. This is achieved by building on existing literature and developing a series of bread-energy system configurations to model energy usage and green-house gas (GHG) emissions at the large (centralised), medium and small scales.
\end{abstract}

Results from the analysis indicate that energy use and emissions can in some instances increase as a result of losing economies of scale through downscaling bread manufacturing. However, the analysis shows that overall energy use and emissions along the bread supply chain are dominated by transportation stages. Thus, RDM opens up new opportunities for reductions in overall energy consumption and emissions, for example by using low carbon vehicles for the transportation of bread and flour at the medium and small scales. Major energy use and emission reductions could also be achieved by reducing car usage if more consumers buy in local bakeries.

The configurations also consider energy use for various bread wastage conditions. Assuming that buying more frequently in local bakeries only the bread that is consumed helps avoiding bread wastage, this would lead to reduced bread purchasing and bread manufacturing, which translates to reductions in energy use and emissions in the modelled configurations. 
Existing data demonstrate that there is a wide diversity across different manufacturing sites in the energy use and associated emissions per loaf of bread produced. The study highlights the opportunities for improvement in the sector if plant move towards the best available manufacturing technologies and practices, and this may be more practical for smaller scale operations. Two hypothetical bread production scenarios show that a greater share of the UK's bread being produced locally could result in a reduction in overall energy consumption and emissions.

\section{Keywords}

Re-distributed manufacturing, water-energy-food nexus, bread, emissions

\section{Introduction}

A number of studies (e.g. McKinsey, 2009; OECD, 2010) have pointed to the links between increased water demand to grow food and for energy generation, while policy advisors, notably Professor John Beddington (2009), have referred to the Water-EnergyFood Nexus as the 'Perfect Storm', pointing out that unless more food, energy and freshwater are available in the next decade while mitigating Green-House Gas (GHG) emissions, shortages around the world will lead to public unrest and international conflict. While there are ongoing commitments to mitigate and adapt to climate change, emerging Nexus issues include securing cheap energy, water and food supplies to meet the demand of a growing global population. Ringler et al., (2013) go further and point out that given the challenges faced by society to minimise our environmental footprint and reduce pressures on natural resources, the inter-connections between the Water, Energy and Food (including land) sectors should be assessed considering human wellbeing and environmental outcomes alongside benefits across the three Nexus sectors.

The Nexus between Food, Energy and Water (FEW) can be considered from several linkages, for example via the embedded energy in potable water (e.g. energy for pumping, treating and distributing water); the water associated with the production of food (both farming/agriculture and food-manufacturing); and the energy involved in growing and producing food, etc. Within the context of the FEW Nexus, the research presented in this paper focused on the energy-food linkage by estimating the energy involved in manufacturing and transporting bread at different scales in the UK. Bread was chosen as the staple food case to study to use in order to answer important contemporary research questions around how and at what scale is more efficient and less polluting to produce food.

Recent research and policy initiatives in the UK that point out that the availability and cost of materials, water, energy, labour and transport, together with the flexibility offered by new technologies, processes, materials, work practices, business structures, value-chains and distribution networks are resulting in more small-scale local manufacturing and businesses (e.g. Foresight report, 2013). The term 'redistributed (or Re-Distributed) Manufacturing' (RDM) refers to this type of manufacturing which is associated with rapid technological, environmental, political, regulatory and social changes in the UK (EPSRC \& ESRC, 2013). Within this background, it is thought that new technologies and ways of working linked to RDM may have potential for localising food production and for reducing negative environmental impacts despite the conventional view that farming and processing bulk ingredients such as milling wheat grain to produce flour, as well as storing agricultural produce may be done more efficiently in centralised large scale facilities.

Down-scaling manufacturing processes could result in greater energy and water consumption due to the loss of economies of scale, and there may also be logistical 
problems (e.g. limited space) to implement efficiencies or install latest technology in small scale local food processing plants. However, RDM can play a role in encouraging local low carbon businesses and an overall reduction in GHG emissions especially in the manufacturing and retailing stages of the supply-chain. Also, having a wider geographical spread of food manufacturing can be positive in socio-economic (e.g. job creation) and environmental terms, because renewable energy and water sources may be used at the local level, and transportation from local plants to retailers and consumers involves shorter distances.

Furthermore, according to a study by WRAP (2014), standard bread is by weight the food item most thrown away, with 460,000 tonnes of standard bread waste generated in the UK in 2012. The study estimates that 350,000 tonnes or $76 \%$ of bread waste is avoidable, as the main reason for bread disposal is consumers purchasing and "not using in time". Purchasing bread more regularly but only when needed from locations closer to consumers (e.g. local bakeries and stores supplied from local baking plants) may help to reduce bread waste, and this could be another argument in favour of re-distributing bread manufacturing.

The research presented in this paper was undertaken as part of the EPSRC and ESRC funded Local Nexus Network (LNN) for Re-Distributed Manufacturing project (see http://localnexus.ouce.ox.ac.uk/feasibility-projects/energy-feasibility-project/).. The study explores the combined energy demands of manufacturing and transporting bread and flour (from mill to retailers) at three different scales, by using data from the available literature to model various RDM supply-chain configurations. These are based on scale of production and are dependent on whether it is flour or bread that is transported, the transportation modality used to deliver either flour or bread to shops, and the means of transport used by consumers when purchasing bread. The energy involved in centralised industrial bread manufacturing and transportation is compared against the energy used in the RDM scenarios and their associated transportation. Thus, the study contributes new data and findings to the existing literature, presenting results on whether manufacturing bread at the small scale, and buying bread locally can have positive effects on energy usage and GHG emissions, which are findings with clear policy implications.

Given this background, the specific research question that this paper aims to answer is around bread RDM and scales of production:

How would decentralised baking plants impact on energy consumption and emissions in the UK's bread supply chain?

\subsection{Background literature on energy and emissions in the bread supply chain in the UK}

The main processes involved in the bread supply chain are: wheat cultivation, wheat milling, bread manufacturing, packaging, transportation, retailing, consumption and waste disposal.

Typically primary ingredients in the bulk of UK bread are flour from wheat (which grows on approximately $30 \%$ of the UK's arable land) and water, $95 \%$ of which is used as rainwater in the wheat cultivation phase in countries such as the UK (Chapagain et al., 2006), with the remaining water added to flour to form bread dough. The UK's wheat yields are amongst the highest in the world, at an average 7.6 tonnes/ ha compared to a world average of 3 tonnes $/ \mathrm{ha}^{1}$. This high yield is attributable to the high inputs of pesticides, growth regulators, and fertilisers used in the UK, which in turn are

${ }^{1}$ http://www.bakersassist.nl/rawmaterials 
responsible for a large percentage of the energy and the main cause of GHG emissions associated with the production of food in general, and bread specifically.

A number of studies have examined the energy and environmental impacts of the UK's food sector. For example, Tassou et al., (2014) offer a literature review of the UK's food manufacturing sector reporting that this accounts for $15 \%$ of the total food-chain energy use, producing $13 \mathrm{Mt}$ of $\mathrm{CO}_{2}$ equivalent emissions ( $\mathrm{Mt} \mathrm{CO}_{2} \mathrm{e}$ ). This study offers a breakdown of the type of fuel used in food manufacturing and also reports that the majority (approximately 68\%) of the energy is used by fuel-fired boilers and heating systems compared to only $16 \%$ of electrical energy used by electric motors, $8 \%$ used by electric heating, $6 \%$ by refrigeration equipment and the rest by air compressors. This paper also reports that energy consumption figures indicate that $80 \%$ of the carbon emissions in food manufacturing are linked to only a few products including bread and fresh pastries, beer and alcoholic beverages, and the production of cheese, dairy, meat and poultry products. They also highlight the vast amounts of food waste that is mainly landfilled. The authors point out the need to use resources more efficiently to minimise waste, and to the potential for producing by-products and energy recovery from waste, as well as they indicate the need to improve technologies and optimise/integrate processes at the plant level.

The energy and GHG emissions of growing wheat have also been examined by studies such as the ones by Charles et al., (2006); Williams et al., (2006); Barling et al., (2011); and Galli et al., (2015. The study by Williams et al., (2006) uses Life Cycle Assessment (LCA) to investigate the resource use and environmental impacts of 10 common agricultural and horticultural commodities including wheat. The study found that producing bread wheat (only $0.7 \%$ of which is organic) consumes 2.5 gigajoules (GJ) of primary energy per tonne of wheat (1.7 GJ per tonne of organic wheat), and produces $0.80 \mathrm{t} \mathrm{CO}_{2}$ (projected global warming potential over 100 years) per tonne of wheat. The majority of the GHG emissions in agriculture are linked to the Nitrogen cycle, with $\mathrm{N}_{2} \mathrm{O}$ and $\mathrm{N}$ from field crops as the gases with most global warming potential e.g. $80 \%$ in the case of wheat production. In terms of energy usage for producing bread wheat, the study reports up to $19 \%$ linked to cultivation, $8 \%$ to harvesting and $8 \%$ and $53 \%$ for pesticide and fertiliser manufacturing, respectively, with the remaining share for spraying, and crop storage.

Other studies on wheat and associated emissions include Galli et al., (2015) that assesses the performance of both global and local wheat to bread chains in various scenarios, and Charles et al., (2006) that undertakes an LCA of the wheat production system for bread-making to ascertain under which fertilization intensities there is sufficient yield increase (crop productivity) to justify additional emissions. Barling et al., (2011) provide data on the areas growing wheat in the UK, prices, uses of wheat and on the bread chain, and report that approximately $60 \%$ of the wheat grown in the UK is destined for animal feed which presents ethical dilemmas.

Specifically looking at bread, research by Beech (1980 and 2006) indicates that bread is the most energy efficient staple food product of an industrialised food production system compared with other foods such as mashed potato, roast beef and reheated canned corn, but baking at home in an electric oven tends to be the most inefficient way of making bread.

Le-bail et al., (2010) report on the energy demand in conventional bread baking versus in the processing of frozen part-baked breads in Europe, and also point out that bread baking is one of the most energy demanding processes in the food sector, compared with other processes such as canning. For partial baking, bread has to be baked twice, and it may also be frozen after part-baking, which will increase the total energy demand. 
Part-baked frozen technology demands about 2.2 times as much energy as conventional bread making processes.

More comprehensive is the study by Espinoza-Orias et al., (2011) which provides the full Life Cycle Analysis (LCA) of white, wholemeal and brown breads including wheat cultivation, wheat milling, bread manufacturing, packaging, transportation, retailing and consumption phases. The study indicates that for all types of bread, the cultivation phase is responsible for the largest percentage of emissions, for example as a result of using fertilizers. This is followed by the consumption phase and the bread manufacturing and transportation stages.

When looking at the emissions specifically associated with bread in the UK, according to WRAP (2013) bread baking (at plant, in-store or at home) is reported to be responsible for $20 \%$ of the GHG emissions of bread, while user behaviour (bread freezing and toasting) and appliance use contribute $25 \%$ of the total GHG emissions, and fertiliser use in wheat growing accounts for $25 \%$ of the total GHG emissions. On bread wasted in the home, WRAP (2014) reports that about 660,000 tonnes of bread (worth $£ 640$ million) is wasted in UK homes every year.

In terms of energy efficiency studies in the bakery sector, the Carbon Trust (2010) study on industrial bread making in the UK points out to energy savings derived from welltested efficiencies and innovative opportunities for carbon emissions reduction across four areas: improving oven combustion efficiency, reducing thermal mass of baking tins, improving control of oven and cooler electrical equipment, and recovering oven heat. The study also shows that there is significant variation in the specific energy consumption depending on differences in the baking operations, plant technology, and site location which influences heating demands.

Also, research has recently been developed in investigating ways of improving the efficiency of industrial processes associated with commercial bread-making. For example, Patton (2013) looked at the energy used in bread manufacturing in order to provide solutions to improve efficiency in commercial bakeries as well as to reduce their environmental impact. Paton identified that between 40 and $49 \%$ of heat is wasted in industrial ovens, and that the proofing (or proving) process, where dough is exposed to specific amounts of heat and humidity to activate yeast, is responsible for $5 \%$ of carbon emissions in bakeries. His research indicates that efficiencies can be made in the 'proofing stage' and that it is possible to reduce airflow by $33 \%$ and electricity demand by over $70 \%$.

The Carbon Trust (2015a) is also working on improving the efficiency of bakery ovens, and research indicates that up to $42 \%$ of energy savings are possible by optimising flue gas. The Carbon Trust (2015b) reported that industry trials demonstrate that improved ventilation in ovens through the use of variable speed drives and sensors can lead to significant energy efficiency improvements when baking bread.

The available literature shows that the agricultural and consumption phases linked to the bread supply-chain have been the subject of various research studies because of their major significance in relation to reducing GHG emissions and energy use. Thus, this study will focus on the manufacturing and transportation stages of bread-making at different scales, where there is room for improvements in terms of energy efficiency and emissions reduction, but which have received less attention previously. To do so, this paper relies on key data published for the UK in the work by Espinoza-Orias et al., (2011), and the study commissioned by the Carbon Trust in 2010 that examined the UK's baking sector as a whole, both of which are good sources of data on energy and 
emissions linked to industrial bread manufacturing Some key papers and data used for this study are reviewed in more detail in the methods section below to avoid repetitions.

\subsection{Description of the case study: bread manufacturing in the UK}

When talking about bread manufacturing itself, the mechanised stages in flour milling require some energy. Grading and cleaning require minimum energy inputs associated with sieving and separating grains, whereas the most energy intensive processes in flour milling are linked to aspirators sucking air to remove dust, and mechanical processes such as blending, breaking, separating and grinding of middling into flour, and packing flour into bags. However, the most energy intensive processes of bread manufacturing are linked to mixing, fermenting, baking and cooling bread.

There are two main types of process used to produce bread: The Bulk Fermentation Process (BFP) and the Chorleywood Bread Process (CBP). The former is the traditional bread making process, while the latter enables large-scale bread making and aids the production of bread with a longer shelf life. The use of mechanical energy in the form of high speed mixing in the CBP removes the need for lengthy bulk fermentation in the traditional process, thus shortening both the fermentation and cooking times and reducing energy inputs. Since the invention of the CBP in 1961, most of the UK's bread dough is fermented using this process, and most of the bread is baked in large centralised manufacturing facilities that sell to supermarkets and some independent shops (Federation of Bakers, 2015), with only a small proportion of bread being baked in in-store/in-supermarket and traditional bakeries as illustrated in Figure $1 .$.

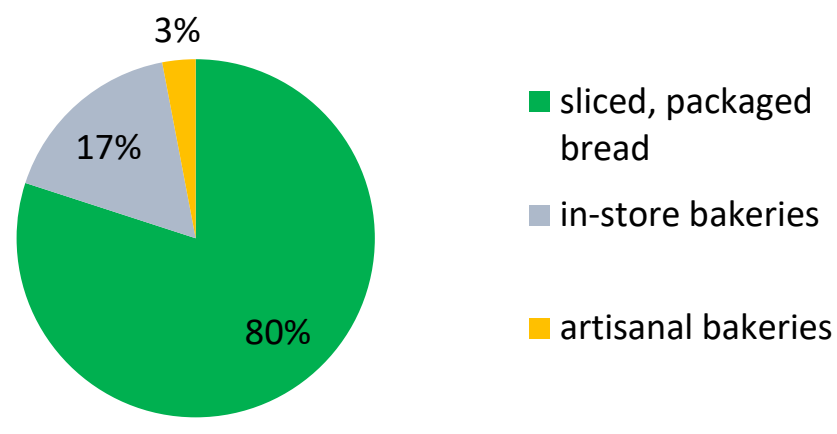

Figure 1: UK's bread consumption by weight. Source: the Federation of Bakers (2015)

In this paper 'bread' refers to unsweetened, leavened 800 gram-loaves, for which the primary ingredients are flour from wheat and water added to form dough using the CBP method. Since the agriculture phase in the bread supply chain has little potential for RDM, this study focuses on the manufacturing and transportation stages of breadmaking (including transportation from flour depots to the final consumer) at different scales, which as mentioned above, have received less attention in previous studies.

Oxford was chosen as the case study place for the bread-baking and transportation configurations, which include transportation of flour from mills to distribution centres and to local bakeries equally distributed over the city of Oxford. It should be noted that bakeries at the local level producing bread with either the BFP or CBP methods already 
exist in some locations, e.g. in Oxfordshire, many of which are artisan bakeries ${ }^{2}$ producing various kinds of high-quality speciality breads and serving a selected niche market of consumers. However, this study focuses on the production of 'main-stream' bread loaves made nearer to the consumer.

Variants for electric vehicles were modelled for the distribution of bread and flour at the medium and small scales in Oxford, while for the small scale bakeries, it was assumed that the consumer walks or cycles to the nearest shop, causing no emissions. This is a credible small scale scenario for a relatively compact city such as Oxford, which is making extensive efforts to de-prioritise motorised vehicles in favour of active transport such as walking and cycling. To illustrate this, Oxford is already considered a 'cycling city' with around $25 \%$ of residents in the city cycling to work ${ }^{3}$.

Waking and cycling, together with car-sharing are on the increase in the UK (Whittle et al., 2019) based on changes in consumers' habits linked to environmental and health awareness (Verplanken et al., 2008), the organisation of the physical environment (Barr and Prillwitz, 2014), improved infrastructure that promotes active transport, and policies to make cities more walkable and bicycle accessible (Hoehner et al., 2005; and Nordh et al., 2017).

Within the UK context, it is noted that in the case of Oxford, the uptake of cycling and walking are positively influenced by the large student population of the city. Also, cycling and walking have been strongly encouraged by local government policy restrictions on parking in the city, pedestrianizing roads, and developing bicycle lanes and footpaths (see the 'Active \& Healthy Travel Strategy' by Oxfordshire County Council, 2016). Furthermore, shopping trends assumed for the small scale scenario are also linked to an extent to the large student population of Oxford, where consumption habits are influenced by the abundance of start-up businesses and varied groups promoting sustainably-produced local food, local markets, independent shops, and emissions-free transport in the city via a wealth of community action groups (see the CAG project ${ }^{4}$ ), and vice-versa.

Changes in UK consumer habits have been observed and national trends indicate that consumers are diversifying where they shop (i.e. progressively buying in more than one preferred supermarket), and are slowly moving towards more 'top-up shopping' instead of one 'main shopping' according to data collected between 2010 and 2014 by Kantar World Panel (2015a and b).

The numerous small supermarkets and independent shops (including local bakeries), together with large proportion of active commuters make of Oxford a suitable and realistic case-study to: 1 ) explore the links between shopping in local shops and reduced energy and emissions from bread manufacturing and transportation at the local scale, 2) compare results at the local level with the situation at the middle and large scales, and 3 ) test if further energy efficiencies can be achieved in bread baking and bread/flour transportation at the local level. Thus, Oxford was chosen as an example of a city striving for more sustainable transport and food manufacturing practices and consumption habits, which may lead the way for other cities and areas in the UK.

\footnotetext{
${ }^{2}$ It should be noted that artisanal has the connotation of producing speciality breads using small scale traditional methods at the local level, but not all small scale local bakeries do artisanal bread. ${ }^{3}$ https://www.oxford.gov.uk/news/article/1029/city and county councils to press government for more i nvestment in cycling infrastructure

${ }^{4}$ https://cagoxfordshire.org.uk
} 


\subsection{Paper outline}

Section 2 describes the methodology applied in this study focusing on a detailed review of key literature and data used in the study, while section 3 describes the detailed steps and assumptions taken to model developed to calculate the energy involved in the baking and transportation steps for five bread supply chain configurations and some hypothetical RDM scenarios. Subsequently, section 4 presents and discusses the results of the configurations analysis and outlines findings of the thought-experiment on hypothetical RDM scenarios. Section 4 also includes a discussion on the potential of using renewable energy sources in localised bread manufacturing. Finally, the conclusions are presented in section 5.

\section{Methods}

This section describes the general methods and data used for the empirical analysis of different bread supply-chain configurations and also for the thought-experiment on hypothetical RDM scenarios that are further detailed in section 3.

In order to investigate the different energy demands of manufacturing bread and transporting flour and bread at different scales, this study applies three distinct scales, namely: large, medium and small scales in bread manufacturing and transportation.

The large scale represents the current prevalent system configuration in the UK with large regional baking plants that supply bread to the regional and city retail locations. Medium scale represents a bakery plant that produces bread for the city scale, and the small scale configuration assumes multiple bakeries in the city so that each neighbourhood has its own bakery. Both the medium and small scales allow for the inclusion of electric vehicles for local transport as an alternative to standard vehicles. Therefore, a total of five configurations were considered (see Figure 2).

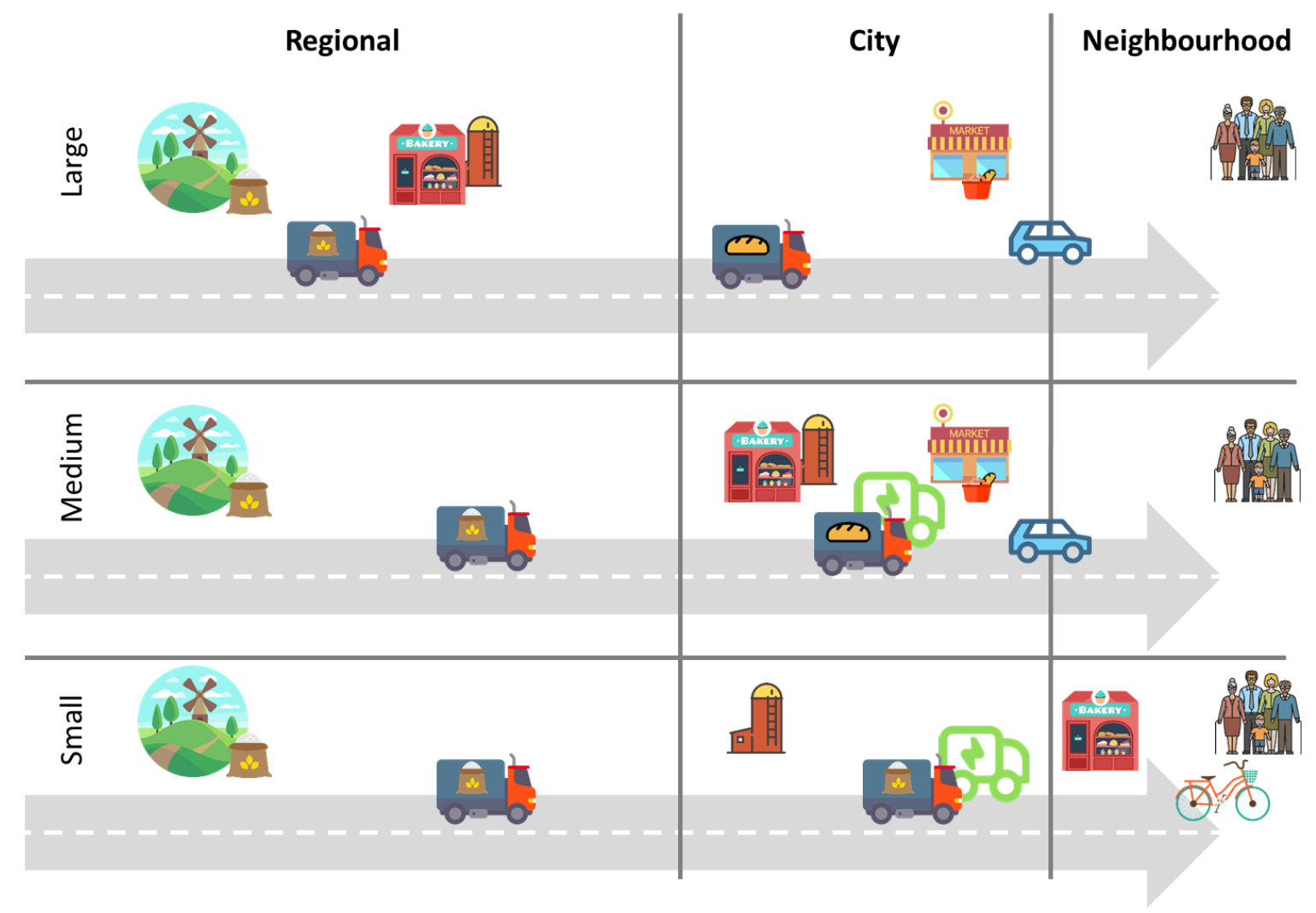

Figure 2: A schematic diagram of the three scales for the bread supply chain configurations analysed. Acknowledgment: icons designed by Freepik from Flaticon 
In relation to the energy involved in these five configurations, it was assumed that the first steps from agriculture to milling remain the same for each configuration. Flour transport was considered to depend on the number of bakeries, their scales and locations. Bread transport covers the logistics from the bakery to the retail locations and depends on the distribution and scale of the bakeries. Retail energy use was assumed to remain the same for each configuration modelled. Consumer transportation to the retail locations was considered to remain the same for the large (regional) and medium (city) scale bakery facilities, since they still supply the same retail locations. Finally, for the small (neighbourhood) scale configuration, it was assumed that consumers can walk or cycle to the nearest bakery.

To assess the energy demand in transportation and evaluate the five configurations defined above, these were modelled using data from the literature consisting of both measurements and modelled results from LCA studies. The city of Oxford was used as a specific case study.

In addition to these five configurations, two scenarios were designed as a thoughtexperiment to model the current energy use specifically linked to bread manufacturing processes in the UK (assumed to be $98 \%$ industrial bread baking), versus a hypothetical scenario, with some variants, where RDM would increase from the current $2 \%$ share to $20 \%$ of total bread supply.

This thought-experiment aims at illustrating two contrasting scenarios for the UK based on available data published and considering only the energy involved in manufacturing processes, without looking at other aspects such as the implications for land-use or how society would get to a higher proportion of RDM locally produced bread. However it is recognised that a move to RDM would have implications in terms of land and resource availability, land-use policy etc. and also, such a move could happen in different ways (i.e. as an incremental change driven by policy and consumers' preferences, or as a single abrupt step-change resulting from a radical policy intervention, a climate shock or conflict affecting global supply chains). It is noted also that the types of energy sources and usage may depend on the chosen pathway for change, which would consequently impact on emissions. In this paper, the thought-experiment scenarios modelled are limited to one moment in time based on the current energy mix and technologies available as reported in key studies.

\subsection{Data sources}

This study is a first attempt to develop a set of consistent scenarios based on data published in various sources, but it is noted that in future research, primary data will need to be collected to undertake more comprehensive modelling. As mentioned in the introduction, a key source of data on energy and bread manufacturing used in this research is the study commissioned by the Carbon Trust in 2010, which reported that the majority of the UK's bread is being baked in large centralised manufacturing facilities that supply bread to supermarkets and a few independent shops. The study states that the UK's industrial bakery sector produces approximately 2.5 million tonnes of baked goods, mainly bread, across 89 sites, and to do so, requires energy use of some 2,000 gigawatt hours $(\mathrm{GWh})^{5}$, which leads to emissions of approximately 570,000 tonnes of $\mathrm{CO}_{2}$ per year, broken down as per Table 1 . These figures were used to calculate energy and carbon intensity factors, and as the benchmark against which to compare energy

\footnotetext{
${ }^{5}$ Note that this data is in final energy use terms, it is not primary energy. In section 3 of this paper for the calculations, energy data are converted into primary energy.
} 
usage and emissions under different manufacturing scenarios. Table 1 also illustrates the mix of energy sources found to be in use in the sector by the Carbon Trust study, which suggests that variations in the types and proportions of energy sources at different baking plants would result in different carbon intensities (tonnes of $\mathrm{CO}_{2}$-e emissions per GWh).

Table 1 Energy use and $\mathrm{CO}_{2}$-e emissions for the UK baking sector based on large scale industrial facilities with flour from centralised mills reported by the Carbon Trust (2010)

\begin{tabular}{|l|r|r|r|r|}
\hline Energy type & $\begin{array}{l}\text { Energy use } \\
\text { (GWh) }\end{array}$ & $\begin{array}{l}\mathrm{CO}_{2} \\
\text { emissions } \\
\text { (tonnes) }\end{array}$ & $\begin{array}{l}\text { Energy intensity } \\
\mathbf{M J} / \mathbf{k g} \text { (kWh/kg) } \\
\text { of produce }\end{array}$ & $\begin{array}{l}\mathrm{CO}_{2} \text { intensity } \\
\text { factors: (tonnes } \\
\mathrm{CO}_{2} \text {-e per GWh) }\end{array}$ \\
\hline Electricity (delivered) & 560 & 300,000 & $0.81(0.224)$ & 536 \\
\hline Natural gas & 1,400 & 260,000 & $2.02(0.560)$ & 186 \\
\hline $\begin{array}{l}\text { Fuel oil and Liquid } \\
\text { Propane Gas }\end{array}$ & 40 & 10,000 & & 250 \\
\hline Totals & $\mathbf{2 , 0 0 0}$ & $\mathbf{5 7 0 , 0 0 0}$ & $\mathbf{2 . 8 8 ( 0 . 8 0 0 )}$ & $\mathbf{2 8 5}$ \\
\hline
\end{tabular}

NOTE 1: Data for 89 industrial bakery sites in the UK emitting 570,000 tons of $\mathrm{CO}_{2}$ to produce a total of 2.5 million tonnes (Mt) of baked goods, mainly bread, using 2,000 GWh of energy per year.

NOTE 2: the data here are in final energy use terms. In section 3 data are converted into primary energy.

The Carbon Trust study (2010) was also used to identify the most efficient baking technologies used in the UK. Based on a graph in the Carbon Trust study, data have been estimated for 13 industrial bakeries of varied scales on specific annual energy consumption (presented as delivered energy per tonne of product produced), and on their annual production, which ranges from approximately 12,000 tonnes per year at the smaller plant to 70,000 tonnes of produce per year at the largest plant. As illustrated in Figure $3 a$, energy use at these 13 plants is not strongly correlated with scale of production. The study found that although there is a trend towards higher energy efficiency with increasing scale of production, energy consumption is also influenced by location, design, age, efficiency and degree of automation of plant technology, as well as operating hours and number and type of products baked.

Considering the fossil fuel and electricity delivered energy data separately, electricity corresponds to between $17 \%$ and $35 \%$ of the energy used in these plants depending on the site, see Figure $3 \mathrm{~b}$. The data in Figures $3 \mathrm{a}$ and $3 \mathrm{~b}$ indicate that in relation to fossil fuels, smaller production plants are less efficient than large plants, whereas in relation to electricity consumption, this tends to be more constant across all plants studied regardless of the scale of production. This is likely to reflect economies of scale that can be achieved in some of the bulk thermal processing stages, such as baking and cooling. 


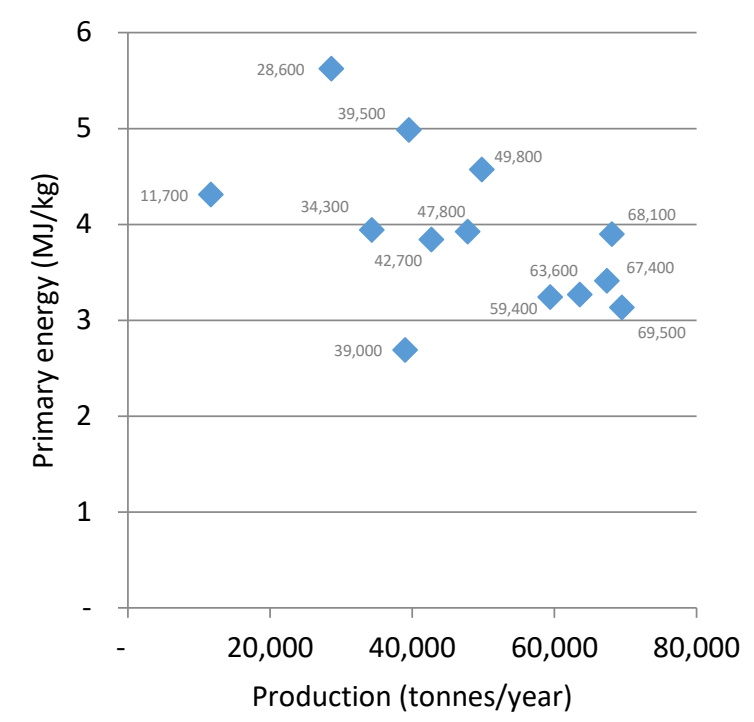

a.

Figure 3 (a) Primary energy per kg of bread and (b) percentage of fossil fuel and electricity (as delivered energy) for the 13 bakeries, based on the Carbon Trust (2010). Primary energy for supplying electricity consumed is shown in $3(b)$. When converted into primary energy, the balance between primary energy for electricity and primary energy for natural gas used shifts upwards as shown by the dash line for each plant.

It should be noted that regarding electricity, the original values were not reported as primary energy in the Carbon Trust study, but in kWh delivered. In this study the values have been converted to primary energy assuming that the electricity is produced with $40 \%$ efficiency -see Figure 3(b). Hence, the total primary energy for these 13 bakeries varies between 2.7 to $5.6 \mathrm{MJ} / \mathrm{kg}$ and is $3.9 \mathrm{MJ} / \mathrm{kg}$ on average.

The most efficient plant among the 13 bakery sites studied is one which operates at the medium-small scale to produce c. 39,000 tonnes of bread per year. This site has the lowest primary energy demand per $\mathrm{kg}$ of product $(2.7 \mathrm{MJ} / \mathrm{kg}$ ) which supports the conclusion of the Carbon Trust's study that operational aspects and type of technology used in bread manufacturing can have a stronger influence in determining energy efficiency than scale of production.

Other data used in the present study were obtained from the published work of Espinoza-Orias et al., (2011) which estimated the carbon footprint and GHG emissions of white and wholemeal bread produced industrially in the UK in a typical large scale bread manufacturing plant. This study included the wheat cultivation, wheat milling, bread manufacturing, packaging, transportation, retailing and consumption processes, and provides data on carbon footprints of white, wholemeal and brown 800-gr bread-loaves produced from UK wheat, sliced and packaged in plastic bags with variations for different slice thicknesses and consumption stages (e.g. if bread is frozen, chilled etc.). EspinozaOrias et al., (2011) indicate that for all types of bread, the cultivation phase is responsible for the largest percentage of emissions, followed by the consumption phase (as a result of toasting, chilling, freezing, re-heating), and the bread manufacturing and transportation stages.

Furthermore, various energy intensities (energy used per $\mathrm{kg}$ mass of produce) linked to different processes, scales and technologies reported in the literature were compared 
and used in this study to model energy usage and emissions. For example, Beech (1980) looked at energy intensities for bread baked in both industrial plants and at home, looking at the full life-cycle of bread, from growing wheat and also only considering the processes after arrival of flour to the plant. In the case of home baking, Beech reports different energy intensities for gas and electric ovens. Energy consumption in home baking is heavily influenced by the technology and practices (e.g. home baking is not usually a continuous process where oven space is fully utilised). Thus the range in energy consumption per $\mathrm{kg}$ of bread is wide with values extending from 4.2 to 54.8 $\mathrm{MJ} / \mathrm{kg}$, and an average value of $26.8 \mathrm{MJ} / \mathrm{kg}$. Braschkat et al., (2004) looked at energy intensities in large plants, medium sized bakeries and home baking comparing regular and organic wheat, and also at home level. Data are reported dependent on whether industrial or domestic wheat milling was used. Le-bail et al., (2010) reported energy intensities for bread produced conventionally in large plants and part-frozen bread products baked in medium-sized bakeries. Figure 4 in the Calculations section below illustrates the energy demands per $\mathrm{kg}$ of produce reported in the various studies, and further details for each of these studies can be seen in Table A.1 in Appendix A.

Specific to the analysis of the five configurations, an LCA study by Thomsson (1999) was used which examined the environmental and energy-conserving options of large and small scale bread supply in Sweden. Data on energy demands related to the bakery step were used respectively in the large and small scale systems modelled in this study.

Furthermore, the work by Masanet et al., (2012) reports generic energy requirements per mass of bread and rolls produced in the US, split by process and type of energy used. Processes included in the study's energy demand analysis are: mixing, fermenting, shaping, proofing, baking, cooling, slicing and packaging. The total energy demand for these processes was used in the evaluation of large scale manufacturing.

The study in Sweden by Andersson and Ohlsson (1999) was also used. This is an LCA study of bread produced at different scales evaluating four variants: two large scale bakeries, a local bakery and home baking. Of the two large scale bakeries, one has national coverage $(30,800$ tonnes of produce per year), while the other has a more regional focus (annual production of 12,800 tonnes). The production capacity of the small scale local bakery used in the study is not specified. Based on a graph provided in the paper, the data have been estimated. The study reports various steps or phases: agriculture, food processing, transportation, packaging and the consumer phase. The energy use in food processing covers wheat milling, bread baking, cleaning in the bakeries and washing dishes in conjunction with home baking. To compare the results with the other data collected, the average energy use for milling was subtracted from the total. This average energy use for milling was estimated to be $0.23 \mathrm{MJ} / \mathrm{kg}$ (Thomsson, 1999 and Espinoza-Orias et al., 2011).

Finally, there are few studies in the literature about energy use in the transportation of bread products and the ones that exist aggregate the embedded energy in transportation stages along the supply chain, thus making it difficult to split the energy use per stage. The Thomsson study of 1999 in Sweden provides some disaggregated data on the energy use related to transportation of grain to retail for large scale bread manufacturing estimating it to be $3.4 \mathrm{MJ} / \mathrm{kg}$. For small scale bread manufacturing this is reported as $2.7 \mathrm{MJ} / \mathrm{kg}$ if the consumer drives and $1.2 \mathrm{MJ} / \mathrm{kg}$ if the consumer walks to the shop. However it is noted when using these data, that the density of population, shopping habits, vehicle size and efficiency, and lifestyles in Sweden in the late 1990s are different to those in the UK in 2017.

In addition to the above energy studies, factors and data collected from multiple sources (e.g. EPA; DEFRA, 2014 and 2015; the Kantar World Panel, 2015a and b; Oxfordshire County Council, Oxford City Council) were used for the transport configurations, together with specific academic publications on consumers transport such as for example the study by Guy (2009), which includes figures on the number of consumer shopping trips 
per year and the percentage of these trips made by car in the UK (c. 62\%). These sources of data for the large and medium, as well as for the small scale transport configurations in Oxford are referred to when describing the calculations in section 3.2 to avoid repetitions.

\section{Modelling bread production scenarios}

Based on the literature and approach discussed in Section 2, this section describes the practical development of the energy analysis for the bread manufacturing and transportation configurations, as well as for the thought-experiment, including specific assumptions and steps in the modelling.

\subsection{Calculations for bread manufacturing}

The review of the available literature for varied processes and techniques to bake bread illustrates the wide range of available studies, technologies and energy demand values linked to bread baking in the UK and other countries. In order to choose appropriate energy demand values for this study, all relevant values found in the abovementioned literature on energy in bread baking which fitted the definition of 'large' and 'small' scales introduced in section 2 were considered, and are included in Figure 4. This also includes values reported in the literature for home baking.

Some studies estimated the energy use based on either electricity or fossil fuel, hence the total value gives a better indication of the energy demand. The total primary energy demand ranges from 1.3 to $6.1 \mathrm{MJ} / \mathrm{kg}$ and from 3.4 to $7.0 \mathrm{MJ} / \mathrm{kg}$ for the large and small scales, respectively (see Figure 4 and Table A.1 in Appendix A). Thus the average energy requirements during baking for large and small scales do not differ very much, and the energy demand for the medium scale was assumed to be the same as for the small scale.

However, energy consumption per $\mathrm{kg}$ of bread in home baking is significantly larger than for the large and small scales bread manufacturing with an average value of $26.8 \mathrm{MJ} / \mathrm{kg}$. The wide range in energy use values for home baking reported in the literature (i.e. 4.2$54.8 \mathrm{MJ} / \mathrm{kg}$-see Figure 4 and Table A. 1 in Appendix A) indicate that home baking is heavily influenced by the technology and practices used. Thus, the most efficient technology together with the most efficient strategy (e.g. full use of oven space) results in energy demands in the same range as small bakeries, although it should be noted that there are limitations in home baking because producing in batches is generally less efficient than continuous production which has no start up time involved. 


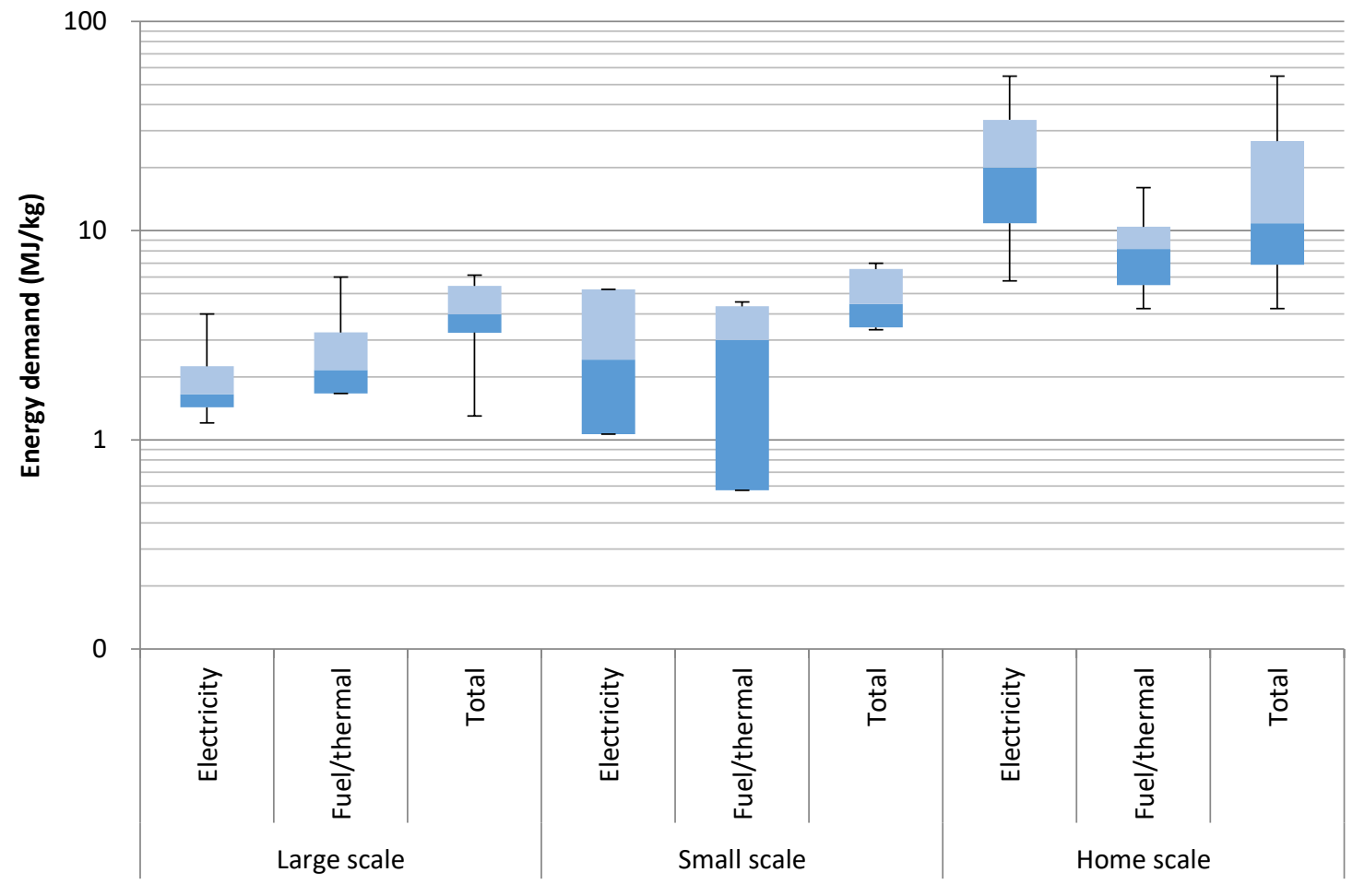

Figure 4: Primary energy consumption (MJ/kg) for bread making at three different scales, plotted on a logarithmic scale. Data from multiple sources (see section 2).

Note: The boundary between the two different blue tones indicates the median value. The darker tone corresponds to the second quartile, while the lighter tone corresponds with the third quartile. The error bars show the minimum and maximum values.

For this study, we opted for the energy demand values most consistent with the scale, situation and manufacturing processes and practices in the UK, ignoring the oldest studies of the $1980 \mathrm{~s}$ and 1990s (linked to old technologies) and the extreme values such as $54.8 \mathrm{MJ} / \mathrm{kg}$ for home baking. Thus, this study modelled the five bread manufacturing configurations using the averages of values reported for the bakery step for the large and small scale systems respectively. For the configurations analysis, the energy used for baking bread at large scale was assumed to be $3.4 \mathrm{MJ} / \mathrm{kg}$, while for the medium and small scale configurations a value of $4.6 \mathrm{MJ} / \mathrm{kg}$ was applied.

For the thought-experiment on RDM hypothetical scenarios, the study uses an average of the energy intensity values reported in the Carbon Trust (2010), Espinoza-Orias et al., (2011), Braschkat et al., (2004) and Le-bail et al., (2010) for non-organic white bread produced conventionally in large plants. A value reported for artisan bakeries in Braschkat et al., (2004) for baking non-organic white bread is used at the medium-small scale, while a value deduced from data reported in the Carbon Trust (2010) study for a medium size plant with optimum technology and practices was also used for comparison. Finally, the energy value reported for home baking non-organic white bread from industrially milled flour in Braschkat et al., (2004) was used in the RDM home baking scenario (see Table A.1 in Appendix A and workings in Appendix B). 


\subsection{Calculations for bread manufacturing locations and transportation configurations}

For the three scales described in section 2, the energy use and impact on emissions related to the differences in transportation were calculated, and the workings and data used are shown in Appendix B, while results are presented via tables and graphs below. A number of assumptions were made to model energy used and emissions as follows:

Oxford, a city with 158,000 residents 6 and an estimated 60,715 households (HH) in 2016 (Oxford City Council, 2011) was used as a case study to quantify some of the variables.

It was assumed that currently the standard loaves are mainly sold by supermarkets. The number of stores of the largest supermarket chains in the example city of Oxford (i.e. Tesco, Sainsbury's, the Co-operative Food, Marks \& Spencer and Waitrose) totals 33 retail locations.

It was assumed that medium-scale bakery facilities supply bread to the same retail locations as the large scale baking facilities, thus the number of retail locations assumed for both large and medium scales in the study is 33.

Based on information from one of the UK's main industrial bread manufacturers ${ }^{7}$, the main difference between the large and medium scales was assumed to be the distances the flour and bread travel outside the city of Oxford. Inside the city, the same retail locations have to be supplied. Table 2 shows the assumed travel distances for the large and medium scale configurations.

\section{Table 2 Distances in the large and medium scale baking facilities' configurations}

Transportation phase

Flour from mill to bakery

Bread from bakery facilities to city

Average distance between retail locations

$\begin{array}{rr}\text { Large scale }(\mathrm{km}) & \text { Medium scale }(\mathrm{km}) \\ 100 & 130 \\ 50 & 8\end{array}$

3

Using the example of Oxford for the small scale bakeries configuration, this study examines the transportation of flour from mills to distribution centres and to the bakeries. It was assumed that flour is transported to a distribution centre near the city which is located $130 \mathrm{~km}$ from a mill. Furthermore, it was assumed that flour is supplied to 25 bakeries in the city. This is fewer than the 33 retail locations assumed for the medium and large scales, because some retail locations are clustered. Therefore, having 25 bakeries equally distributed over a city like Oxford seemed realistic. Since space is expensive in the city, it was assumed that a typical bakery has a $1 \mathrm{~m}^{3}$ of space to store flour.

Assuming that a small truck can deliver the flour from the distribution centre to multiple bakeries during one roundtrip, then the number of roundtrips depends either on the

\footnotetext{
${ }^{6}$ https://www.oxford.gov.uk/info/20131/population/459/oxfords population

7 'There are two sides to Distribution - Primary and Secondary. Primary makes sure products are smoothly transported between our 12 bakeries and 14 depots to our despatch teams, who collate and distribute products so our trunking teams can fulfil onward internal deliveries. Secondary distribution takes products to customers from big multiples to smaller convenience stores, with multi-drop deliveries by the Sales Delivery team'. Source: http://www.warburtons.co.uk/warburtons-careers/meet the family/distribution.html\#sthash.VUIgL8kQ.UNjvaKZZ.dpuf
} 
limitation of space in the bakeries or on the limitation of the truck's allowed weight. It was assumed that a small truck can transport a maximum of 3 tonnes of flour. A roundtrip was assumed to have an average distance of $30 \mathrm{~km}$. Since flour can be stored at the bakery itself, the transportation of flour is less time critical than the distribution of bread, which occurs mainly early in the morning. This means that it is possible to supply all 25 bakeries with flour using only one truck to transport the necessary 6.5 tonnes of flour per day.

For the electric variants, it was assumed that the transportation of bread for the medium scale bakeries, and the transportation of flour from the distribution centre to the small scale bakeries would be carried out by electric vehicles.

For the small scale bakeries, it was assumed that the consumer walks or cycles to the nearest shop, causing no emissions.

To be able to estimate the total travel distances required to distribute bread, data used as inputs are shown in Table 3. It was assumed that a truck can contain 4,000 800 gloaves of bread ${ }^{8}$. Based on the population and household data for Oxford detailed above, for this study it was assumed that $0.13 \mathrm{~kg} / \mathrm{HH} / \mathrm{d}$ are consumed in 60,715 households, thus $7,892 \mathrm{~kg}$ of bread is consumed in households in Oxford every day. This translates as $9,865800 \mathrm{~g}$-loaves per day, plus a safe daily surplus of bread that most shops require. Thus it was assumed that $10,000800 \mathrm{~g}$-loaves of bread have to be supplied to the 33 retail locations in Oxford every day, and would be supplied by four trucks (see data in Table 3).

\footnotetext{
${ }^{8}$ The figure of 4,000 loaves/day has been estimated based on information from the website of Warburtons (large scale UK bakery) stating that 2 million products per week are delivered to 1,500 customers via 71 routes: ("I'm a Sales Team Leader at Bolton Bakery. I manage a team of drivers and the sales operation from 4am, with 115 staff, 71 routes across the North West and just over 1,500 customers. We deliver around 2 million products a week, and I deal with everything from customer service to staff and resource management"). http://www.warburtons.co.uk/warburtonscareers/meet the family/distribution.html\#sthash.VUIgL8kQ.6gk3S7zN.dpuf

Thus, assuming that all products are 800 -g bread loaves, and that they produce 7 days each week, the daily production is estimated at 285,714 loaves per day. Assuming that each route has its own truck, this means 4,024 products per truck (and route) with 21 customers per route.
} 
Table 3 Assumptions used in the bread manufacturing and distribution configurations

\begin{tabular}{|c|c|c|}
\hline Description & Value & Unit \\
\hline Consumer shopping distance, one-way ${ }^{a}$ & 6.8 & $\mathrm{~km}$ \\
\hline $\mathrm{kg}$ bread daily consumption per person ${ }^{b}$ & 0.05 & $\mathrm{~kg} / \mathrm{pp} / \mathrm{d}$ \\
\hline kg bread per household per day & 0.13 & $\mathrm{~kg} / \mathrm{HH} / \mathrm{d}$ \\
\hline loaves per household ${ }^{c}$ & 0.16 & 800g-loaves/HH/d \\
\hline $\begin{array}{l}\text { loaves per truck (own estimate based on information from } \\
\text { Warburtons } s^{7} \text { ) }\end{array}$ & 4,000 & 800g-loaves/truck \\
\hline truck payload for flour ${ }^{d}$ & 29 & tonnes \\
\hline wheat flour for $1 \mathrm{~kg}$ of bread & 0.67 & $\mathrm{~kg}$ \\
\hline flour loss during processing (own estimate) & 3 & $\%$ \\
\hline flour density & 593 & $\mathrm{~kg} / \mathrm{m}^{3}$ \\
\hline $\begin{array}{l}\text { op -per person; } d \text { - day; HH-household } \\
\text { Source: Guy (2009) } \\
\text { Source: Defra (2015). The bread consumption figure of } 0.05 \mathrm{~kg} \\
\text { less than two 28g-slices per person per day, which although it } \\
\text { purchased in SE England plus bread eaten out. It should be not } \\
\text { which accounts for the low average value. } \\
\text { Based on average of } 2.6 \text { persons per household }(\mathrm{HH}) \text { as per da } \\
\text { Source: McKinnon and Piecyk (2010) }\end{array}$ & $\begin{array}{l}\text { Source: Defra (2015). The bread consumption figure of } 0.05 \mathrm{~kg} \text { per person per day }(\mathrm{pp} / \mathrm{d}) \text { is equivalent to } \\
\text { less than two } 28 \mathrm{~g} \text {-slices per person per day, which although it sounds low is based on data for bread } \\
\text { purchased in SE England plus bread eaten out. It should be noted that some people don't eat bread at all, } \\
\text { which accounts for the low average value. }\end{array}$ & $\begin{array}{l}\text { day ( } \mathrm{pp} / \mathrm{d} \text { ) is equivalent to } \\
\text { ed on data for bread } \\
\text { ople don't eat bread at all, } \\
\text { ty Council (2011) }\end{array}$ \\
\hline
\end{tabular}

Regarding $\mathrm{CO}_{2}$ emissions, a study by The Greenhouse Gas Protocol shows default fuel economy factors for different types of mobile sources and activity data based on averages from the USA's Environment Protection Agency's 2001 Guides (EPA, 2008a and EPA, 2008b), which also include emissions for different car sizes in the city (e.g. small, medium and large car). For the $\mathrm{CO}_{2}$ emissions of consumer cars, the value of $228.9 \mathrm{~g}$ $\mathrm{CO}_{2} / \mathrm{km}$ (368.4 $\mathrm{g} \mathrm{CO}_{2} / \mathrm{mile}$ ) for the small car in the city from the USA- EPA 2001 Guide (EPA, 2008a) was used, as it was assumed that the average car in Oxford is equivalent to a small car in the USA.

However, the $\mathrm{CO}_{2}$ emissions of a HDV were not supplied in the same source, and so a figure from a study by McKinnon and Piecyk (2010) reporting $\mathrm{CO}_{2}$ emissions of $62 \mathrm{~g}$ $\mathrm{CO}_{2}$ /tonne-km for 40-44 tonne trucks was used in this study. Table 4 shows average emissions in $\mathrm{g} / \mathrm{km}$ for a car, light-duty vehicle (LDV) and a heavy-duty vehicle (HDV) used in this study. Furthermore, it was assumed that $62.1 \%$ of the shopping trips are made by car in the UK based on the study by Guy (2009).

This study is based on existing published data, however it is acknowledged that how the share of shopping trips' emissions are allocated to the loaf of bread will make a significant difference to the results. This is especially the case given how significant are the energy and emissions associated with the transport stage (see the dashed bars in Figures 5 and 6 ), thus this issue will be discussed further in the sub-section below.

It should also be noted that emissions depend on many factors and that the focus of the automobile industry on energy-efficiency and emissions reduction in recent years has had a positive effect on the emissions of newer vehicles. 
Table 4 Average emissions ( $\mathrm{g} / \mathrm{km}$ ) for a car and heavy-duty vehicle (HDV)

\begin{tabular}{|c|c|c|}
\hline Pollutant & Car & HDV \\
\hline Volatile Organic Compounds (VOC) & 0.642 & 0.278 \\
\hline Total Hydrocarbons (THC) & 0.669 & 0.281 \\
\hline Carbon Monoxide (CO) & 5.841 & 1.436 \\
\hline Nitrogen Oxides (NOx) & 0.431 & 5.352 \\
\hline Particulate Matter $<=10$ microns (PM10) & 0.003 & 0.126 \\
\hline Particulate Matter $<=2.5$ microns (PM2.5) & 0.003 & 0.118 \\
\hline Carbon Dioxide $\left(\mathrm{CO}_{2}\right)$ & 229 & $\begin{array}{l}62 \mathrm{~g} \mathrm{CO}_{2} / \text { tonne-km for } 40-44 \\
\text { tonne trucks reported by } \\
\text { McKinnon and Piecyk (2010) }\end{array}$ \\
\hline
\end{tabular}

The electric vehicle was assumed to be a medium duty truck with an average range of $145 \mathrm{~km}$ (90 miles) on a battery of $99 \mathrm{kWh}^{9}$. An actual range of $80 \%$ of this average range, thus $116 \mathrm{~km}$, was assumed for this study since the truck is mainly used in a city which is less energy efficient due to frequent stops and accelerations. Furthermore, the average UK grid emission of $412 \mathrm{gCO}_{2}-\mathrm{e} / \mathrm{kWh}$ was applied ${ }^{10}$.

\subsubsection{Assumptions and calculations for the 'Retail to consumer' energy use}

The total primary energy consumption based on the use of cars for the 'Retail to consumer' phase for the large and medium scales is represented in Figure 5, and the associated emissions are depicted in Figure 6 . For the small scale configuration it was assumed that the shopping trips would be made walking or by bicycle, and so consumers' transportation energy use was modelled without consumer car transportation. This is shown in Figures 5 and 6, where the dotted bars are missing for the small scale configuration compared to the large and medium scale configurations.

The 'Retail to consumer' total energy consumption of $96,458 \mathrm{GJ}$ was estimated based on the 'Retail to consumer' distance of $28,900,000 \mathrm{~km} /$ year estimated for Oxford and the primary energy consumption of gasoline cars per $\mathrm{km}$ which is $3.34 \mathrm{MJ} / \mathrm{km}$.

The 'Retail to consumer' distance of 28,900,000 km/year was estimated for shopping trips within the city of Oxford considering only the trips when consumers shop for bread (although not for bread only), by multiplying the number of households in Oxford $(60,715$ households) by the average shopping travel distance of 766.5

$\mathrm{km} /$ year/household, by $62.1 \%$ which is assumed to be the percentage of shopping trips made by car as reported by Guy (2009). The number of households was calculated from a population for Oxford of 158,000 at 2.6 people per household according to Oxford City Council data ${ }^{11}$.

\footnotetext{
${ }^{9}$ http://www.evi-usa.com/LinkClick.aspx?fileticket=SyZhwUVqNJs\%3d\&tabid=83

${ }^{10}$ https://www.gov.uk/government/publications/greenhouse-gas-reporting-conversion-factors-2016

11 https://www.oxford.gov.uk/info/20131/population/459/oxfords population
} 
The shopping travel distance of $766.5 \mathrm{~km} /$ year/household used in this study is based on a return trip of $13.6 \mathrm{~km}$ (see Guy (2009) who reports $6.8 \mathrm{~km}$ one-way journeys for which shopping was the main purpose) multiplied for 1.08 loaves of bread purchased per household per week based on $50 \mathrm{gr}$ per person per day consumed in the UK (see data from DEFRA, 2015). Thus, this shopping travel distance to buy bread has been calculated based on published data on bread consumption per person and on journey distances, and it is considered a reasonable estimation of the proportion of shopping trips made by car to the retailer to buy bread, when compared with the shopping distance travelled by car by consumers for all shopping activities which totals 1801 $\mathrm{km} /$ year/household. This figure itself represents a $62.1 \%$ of all shopping trips (by car and other transport means) undertaken per household per year, based on the return trip distance of $13.6 \mathrm{~km}$ (Guy, 2009) and an average of 213 car shopping trips per year per household, calculated from the figures of 219, 221 and 200 reported by Guy (2009), Kantar World Panel (2015a) and the Food Ethics Council ${ }^{12}$ respectively (see data and workings in Appendix B).

The allocation of impacts is a common problem in LCA studies and many different approaches can be taken ${ }^{13}$ : In the case of emissions allocated to bread transportation from 'Retail to consumer', the energy used by private cars could be divided by the average number of grocery items purchased including bread, for example dividing by an average of 10.5 items per shopping trip as reported in the UK by Kantar World Panel (2015a). However, the argument against doing this, is that the costumer might still need to do at least some of the shopping trips for the other grocery items, while the counter-argument is that maybe all, or at least some, trips to the supermarket may be avoided if consumers bought bread, and possibly other regular items such as milk, cereal and eggs, locally.

In view of this ambivalence, it was decided to model the configurations at the local level as a possible realistic scenario where car trips would be cut down all-together if bread and other 'top-up' items could be shopped locally by foot or bicycle. Thus, Figures 5 and 6 do not include 'Retail to consumer' energy and emissions, respectively, at the small scale. In contrast, Figure 8 includes the energy allocated to 'Retail to consumer' transport for the large and medium scales, as well as for the small scale with a reduction of $5 \%$ of the shopping trips. This is to illustrate the significant reductions that can be achieved just by cutting down on some shopping trips if consumers leave their car at home to shop bread and other items more locally.

The primary energy consumption of gasoline cars of $3.34 \mathrm{MJ} / \mathrm{km}$ was calculated based on average fuel consumption data for passenger gasoline cars of $34.2 \mathrm{MJ} / \mathrm{I}^{14}$ and 0.098 $1 / \mathrm{km}^{15}$. The 'Retail to consumer' total primary energy is plotted as TJ in Figure 5 to ease graphic representation.

\section{Results and discussion}

As discussed in the introduction, although water and energy efficiency per unit of production is very important for the pre-milling stage of bread production, the upstream boundary of this study was set from 'mills' to 'homes' due to the fact that to date, less attention has been paid to the milling and post-milling stages of the bread supply-chain. Results of the energy use and GHG emissions analysis for the five configurations modelled in Oxford are presented below, including results for different population sizes

\footnotetext{
${ }^{12}$ http://www.foodethicscouncil.org/uploads/publications/Snapshot(web) $0 . p d f$

${ }^{13}$ https://www.pre-sustainability.com/news/finding-your-way-in-allocation-methods-multifunctionalprocesses-recycling

${ }^{14}$ http://www.ghgprotocol.org/files/ghgp/tools/co2-mobile.pdf

${ }^{15} \mathrm{https://www3.epa.gov/otaq/consumer/420f08024.pdf}$
} 
and progressively reduced bread waste. Furthermore, the energy used when including consumers' car transport in the configurations analysis is also presented in this section.

\subsection{Energy use and emissions for configurations in Oxford}

The energy and emissions results for the modelled configurations for Oxford are shown in Figures 5 and 6. The emissions associated with the consumer's shopping trip (referred to as 'Retail to consumer') proved to be very high in comparison to those of the rest of the transport stages of the supply chain, and so these values have been plotted as dashed bars on the second $y$-axis in Figures 5 and 6 . It should be noted that although a reasonable estimation was made to calculate energy use related to bread shopping, due to the data available being for all shopping activities, the 'Retail to consumer' energy and emissions in Figures 5 and 6 reflect shopping trips when bread was bought, but not only bread.

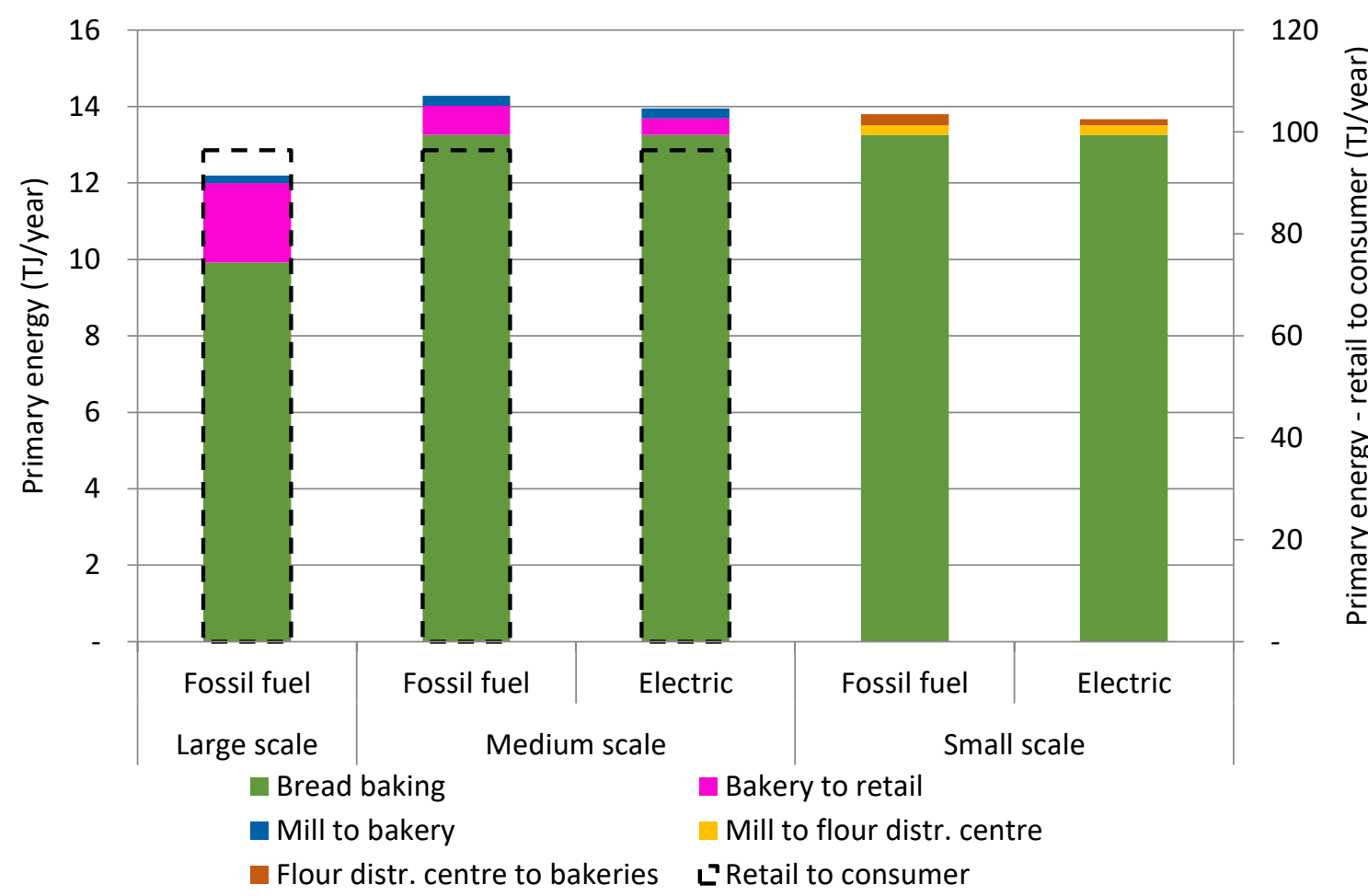

Figure 5: Primary energy consumption (TJ/year) for the five configurations at three different scales 


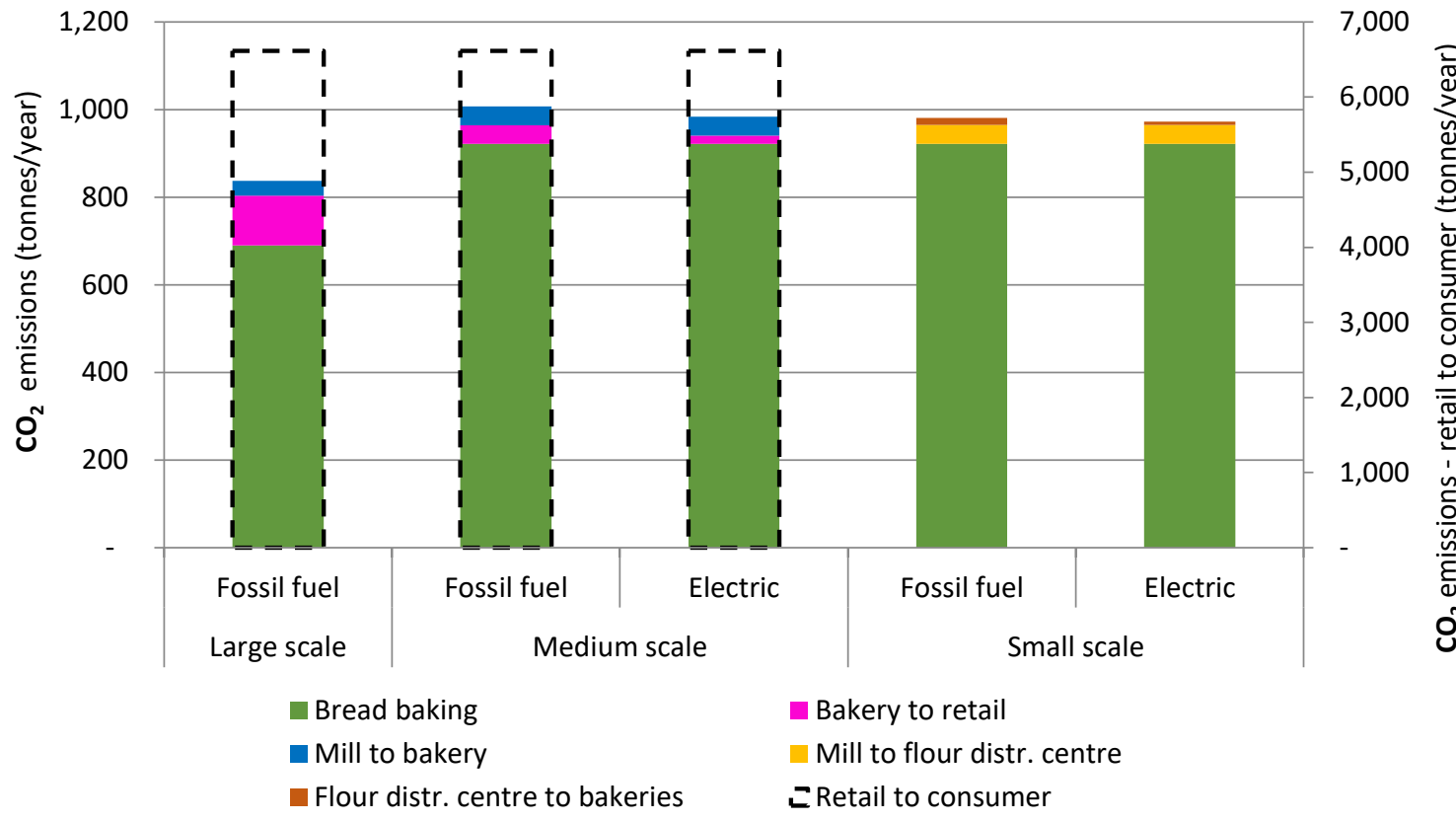

Figure 6: $\mathrm{CO}_{2}$ emissions (tonnes/year) for the five configurations at three different scales

As illustrated in Figures 5 and 6, the energy and emissions involved in consumers driving to retailers in the large and medium scale configurations exceed by far the energy and emissions associated with transporting flour from the mill to baking plants, baking the bread, and transporting the bread to the supermarkets. However, as mentioned above, it should be noted that for this analysis it was assumed that $62.1 \%$ of the shopping trips in the UK are made by car based on the study by Guy (2009). Results would vary significantly if the assumption was that in the medium scale, for example, the majority of bread shopping trips involved walking or cycling instead of driving.

Furthermore, electric vehicles transporting bread from baking plants to retailers in the medium scale can reduce the energy use and emissions, and equally, using electric vehicles for transporting flour from distribution centres to bakeries in the small scale also leads to energy and emissions savings in the system.

Also, $\mathrm{CO}_{2}$ and other emissions related to consumers' transportation are avoided altogether for the small scale configurations with the assumption that consumers walk or cycle to the local bakeries to purchase their bread.

Figure 7 illustrates other emissions for the five configurations at three scales for Oxford, for both the heavy-duty vehicles and cars. It should be noted in relation to transportation from regional large scale bakeries and mills to retail locations and medium-small bakeries, that truck sizes were fixed in the model, so for example, depending on the amount of bread to be transported, the truck has a certain loading ratio and this can cause some step changes. 


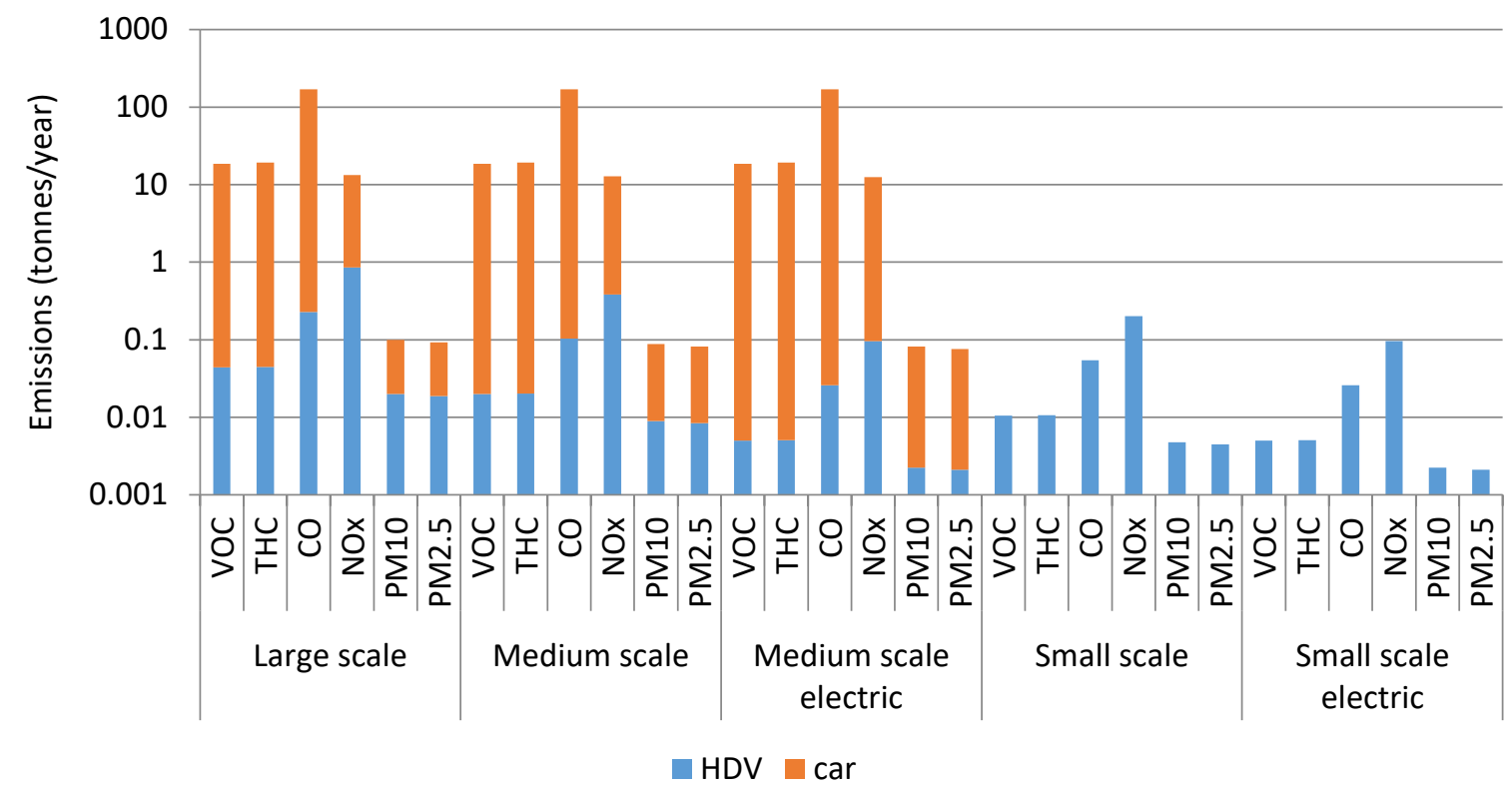

Figure 7: Other emissions (tonnes/year) for the five configurations at three different scales, plotted on a logarithmic scale (see Glossary for abbreviations)

\subsubsection{Reduced consumers' car transport}

For the configurations analysis, it was assumed that in the small scale configuration consumers will leave their car at home and will either walk or cycle to the bakery. In practice many people may still use their car since they may need other grocery items as well. However, since the energy use and impacts involved in consumers' transportation is high (see Figures 5 and 6 ), even a small reduction in car usage can make a difference.

Figure 8 shows this difference with a $5 \%$ reduction in consumers' car transportation, and it should be emphasised that a reduction of just $2 \%$ in private car use would already result in a lower overall energy demand than the large scale configuration.

This is despite the fact that large scale bakeries have higher baking efficiency that outweighs the extra energy for transportation to the towns and cities they serve (assumed to be in a $50 \mathrm{~km}$ radius). As they serve many people in a region, their higher baking efficiency and economies of scale are outweighed by the greater energy consumption during the 'Retail to consumer' phase. 


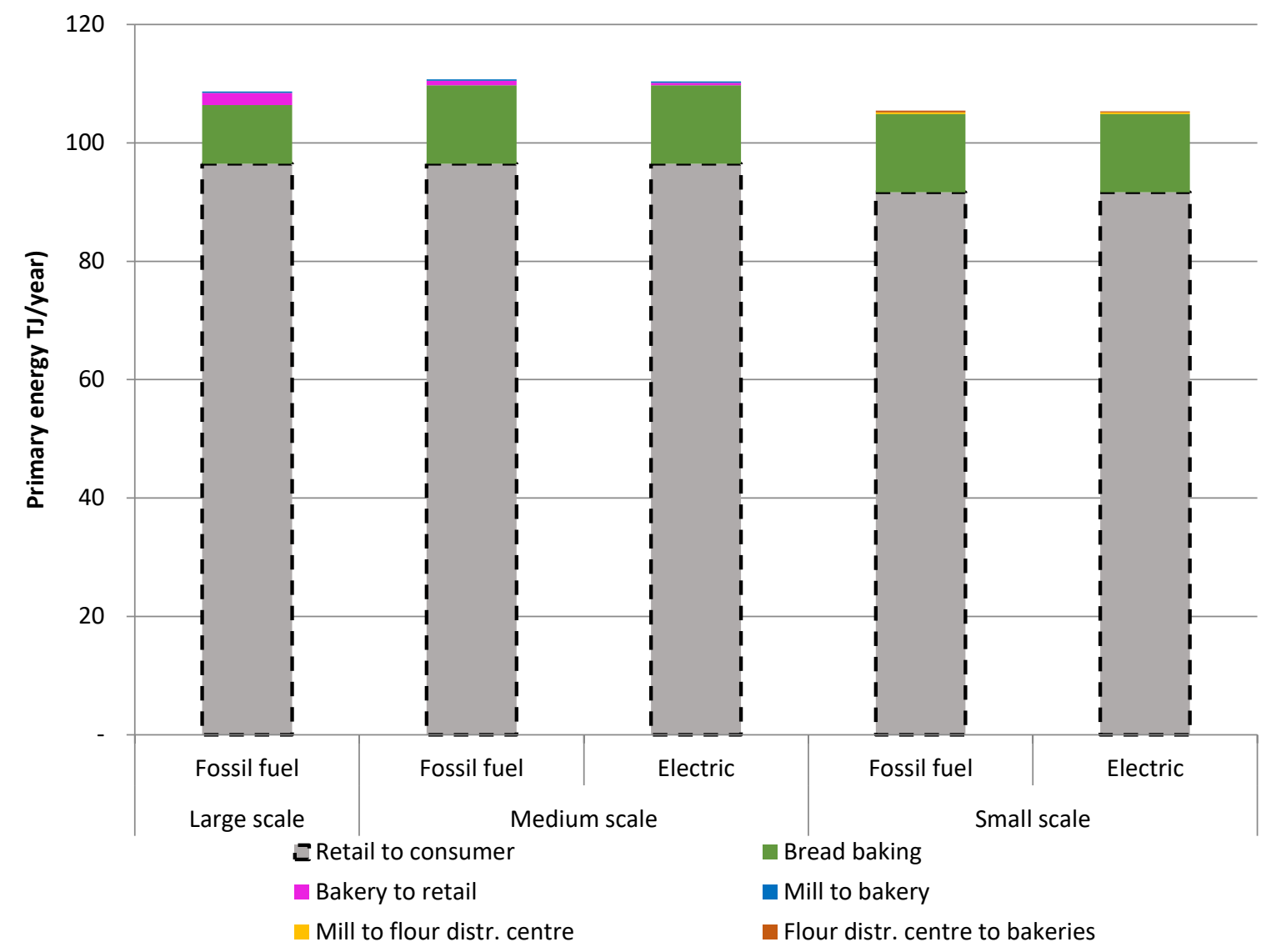

Figure 8: Primary energy consumption for the five different configurations at three different scales with 'Retail to consumer' transportation included in all three scales. Consumer transportation in the small scale configuration has been assumed to be $5 \%$ less than the large and medium scales to illustrate the energy reductions that can be achieved if some shopping trips are cut down, and consumers walk, cycle or take the public transport instead of driving their cars

From the transportation analysis, it can be concluded that electric vehicles would have a positive effect in energy used for transportation of flour and bread at the medium and small scales (see Figure 5), and that as a result of distances travelled by consumers, the small-scale bakery has an advantage over the medium and large-scale variants, thus reducing driving to buy bread at all scales significantly reduces the overall energy use (see Figure 8 ). These could be important factors that help reduce energy consumption and emissions in the future, and if mitigating air pollution becomes a higher priority, a shift towards local scale bakeries and electric vehicles (including trucks with limited drive-range) could favour RDM. Trucks and vans might also be fuelled by hydrogen in the future, and depending on fuel cost, RDM might also be economically advantageous.

\subsubsection{Reduced waste}

Based on data from WRAP ${ }^{16}$ on total waste of standard bread (defined as broader than loaves only) in UK households of 460,000 tonnes, and Defra's Family food statistics for

${ }^{16}$ http://www.wrap.org.uk/content/household-food-and-drink-waste-uk-2012 
$2014^{17}$ about the share of loaves (white, brown, wholemeal) within the standard bread category, reported as 76\% for South East England, then the bread waste per household in the UK is:

$460,000 \times 76 \% / 27,210,165$ households $(2014)=12.9 \mathrm{~kg} /$ household/year

This equals 784 tonnes of bread wasted for Oxford's population per year, compared to Oxford's total bread consumption of 2870.6 tonnes based on data for South East England reported also in Defra's Family food statistics, i.e. 784/2870.6 $=27 \%$.

Thus, it was estimated that in Oxford approximately $27 \%$ of the purchased bread loaves end up as waste.

Since reduced bread waste and thus less bread consumption (i.e. purchases) would also mean a reduction in bread production and transportation, the whole supply system is influenced. Thus for each percentage of bread waste reduction, the primary energy demand for each configuration was calculated for the whole system and results for the city of Oxford are shown in Figure 9.

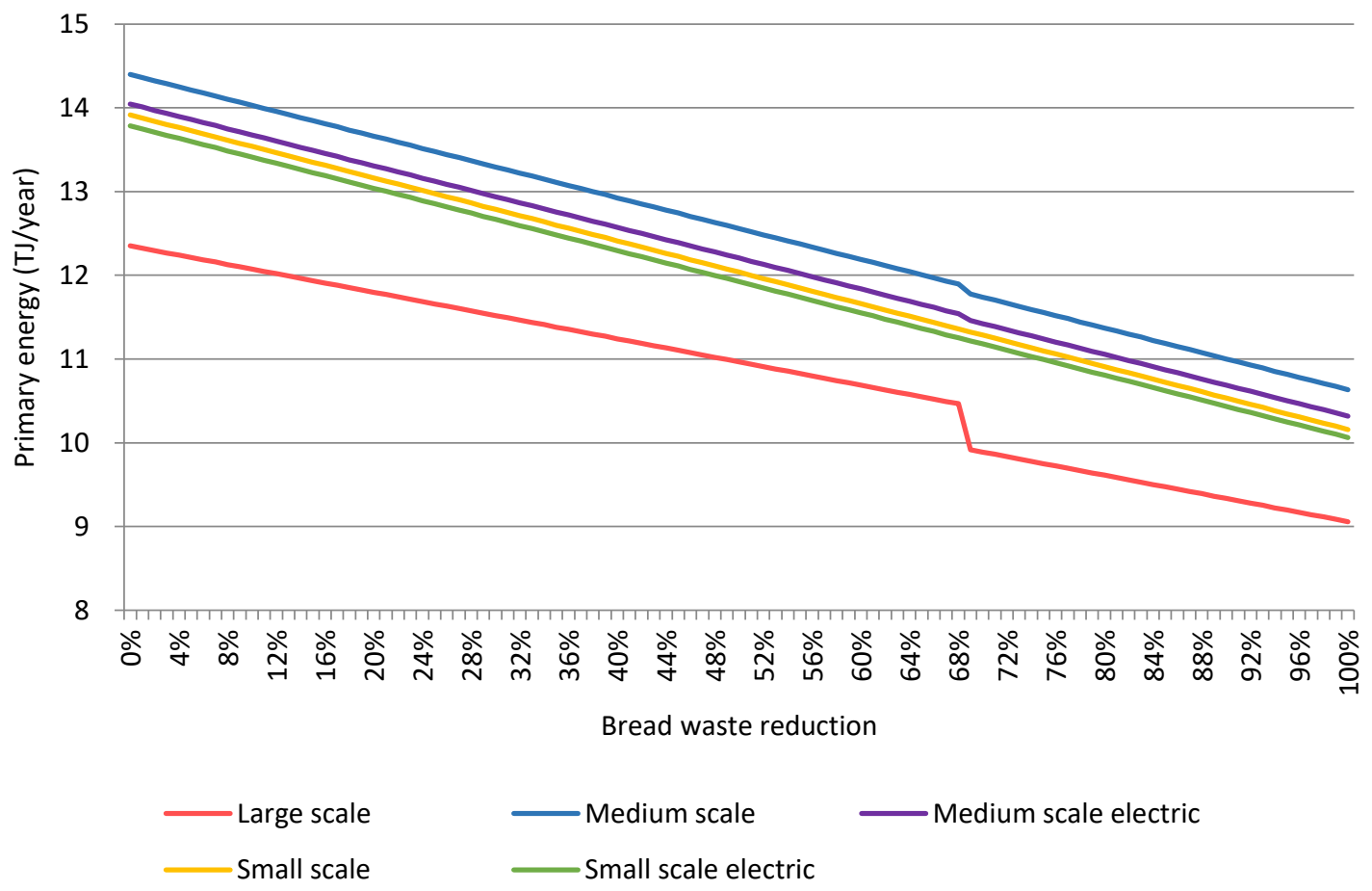

Figure 9: Primary energy consumption (TJ/year) for the five configurations for different levels of bread waste reduction, excluding consumer transportation, based on the city of Oxford

Figure 9 shows a progressive decrease in energy use as bread waste is reduced.

Avoided bread waste is assumed to lead to fewer purchases and consequently reduced bread manufacturing at all scales. It seems reasonable to assume that bread wastage can be reduced more easily in a scenario in which small scale bakeries are prevalent, as

${ }^{17}$ https://www.gov.uk/government/statistics/family-food-2014 Purchased quantities of household food \& drink by Government Office Region and Country plus Purchased quantities of food and drink eaten out in the UK, both for 2014 
these may more easily produce bread on demand, in smaller sizes and tailored to customers' preferences (e.g. based on dietary requirements). It is also assumed that consumers buy less bread (only the bread they are going to consume in the short term) if buying on a daily basis at local bakeries, consequently reducing bread waste.

Furthermore, if waste is reduced sufficiently, the number of trucks used can eventually also be reduced which is shown in Figure 9 as the sharp inflection at $68 \%$. Based on Figure 9 , if waste could be reduced by $45-50 \%$ for the small scale variants, total primary energy use would be equivalent to that for the large scale system with the existing waste levels. Much larger energy savings would result from reducing bread waste at the larger scale, and consequently $\mathrm{CO}_{2}$ emissions would be lowered too. For the smaller scales emissions would remain lower than for the large scale configuration, and in the same way as for energy use, reducing bread waste has the greatest effect in lowering emissions at the large scale as a result of reduced bread purchases and production.

\subsubsection{Barriers in the configurations analysis}

The analysis of bread manufacturing and transportation configurations described above highlights some barriers. For example, to operate flour distribution efficiently at a local level, either local bakeries should co-operate or all/many of the local bakeries should be part of the same chain to share flour delivery trucks. Also, baking and selling bread at a small scale may face difficulties in terms of the sustainability of the bakeries' business case. For example, in the case study of Oxford with 25 small scale bakeries, if each bakery would need to produce and sell approximately 400 loaves of bread per day to cover expenses and make some profit, this may be unrealistically large and impossible for some bakeries. In this context, emerging technologies such as data-driven flexible robotics (smart industry) might offer opportunities for businesses.

Robotics are already in place for bread making via fully automated compact machines that mix, knead, shape and bake bread loaves in front of customers within supermarkets or other shopping outlets (e.g. see details of the 'Breadbot'18), and it should be noted that although these may operate at the local scale, the business model can operate as a large company with a chain of local baking facilities. It should also be noted that although new technologies can be expensive to introduce, they can reduce labour costs, while custom-made ingredients and fresh products made for specific diets can justify a premium price, thus increasing revenue. Also baking on demand can reduce waste and therefore costs of production. Regarding other trade-offs, it is important to recognise that new technologies such as robotics may impact on jobs with some posts disappearing, while other jobs may be created, however, this aspect is beyond the scope of this study.

Finally, in this study it was assumed that the presence of local bakeries will remove the use of cars for buying bread. However, shopping for other goods will still take place probably following existing consumer habits (e.g. weekly shopping in supermarkets and large retailers), thus the overall positive impact of more localised bakeries on energy use and emissions is difficult to ascertain accurately at this point, and will be determined also by possible shifts in consumer habits (e.g. consumers preferring to buy fresh bread more frequently and locally when walking to and from work if more bakeries are available at the neighbourhood level).

Nevertheless, it is possible that the overall number of car journeys would be reduced if local bakeries sell milk, eggs and other basic goods in addition to bread, and as a result of cultural influences (e.g. preference for more French-style shops). The presence of local bakeries in itself may encourage local residents to buy daily in their neighbourhoods thus encouraging the proliferation of other local businesses such as deli-

${ }^{18}$ https://www.wilkinsonbaking.com/the-mini-bakery 
shops, butchers and fish-mongers. This is already being observed in affluent neighbourhoods in most towns and cities in the UK, and although it is far from changing the overall retail landscape, these trends can further contribute to reduce shopping carjourneys. Additionally, other emerging issues such as reducing urban air pollution and tendencies such as internet shopping and grocery delivery services also have great potential to impact the energy demand for transportation, especially since these are becoming increasingly popular and may be very efficient if they were to replace individuals shopping by car (Coley et al., 2009).

\subsection{A thought-experiment on further opportunities for energy and emissions reduction}

Building on the data from literature reviewed, e.g. Carbon Trust (2010), and collected for the Oxford-based configurations described in previous sections, a thought-experiment was carried out to estimate the energy and GHG emissions involved in manufacturing bread under hypothetical scenarios where RDM would be more widespread. A series of 'what-if' scenarios were modelled such as: what-if $20 \%$ of bread was locally produced at the small and home scales, compared with, for example, an assumed current share of $2 \%$ in Oxford?

The exercise, not surprisingly, indicated that the annual energy usage and associated emissions would increase significantly as a result of using less efficient technologies and practices to produce $20 \%$ of the bread in batches in medium-small local bakeries and in private homes, instead of producing bread continuously in highly efficient large scale industrial facilities. This is illustrated in Figure 10 scenarios 2a (medium-small scale) and $2 \mathrm{~b}$ (home-baking) in comparison to scenario 1 which represents the current annual energy use situation based on an assumed $98 \%$ of the bread consumed in the UK being produced in large scale industrial baking plants with only $2 \%$ of bread being produced at the medium and small scales including some home-baking.

Home baking, as an ultimate endpoint of RDM for bread, especially threatens significant energy and emissions increases because the ingredients still need to be bought and transported home, and also because bread is normally baked in relatively inefficient appliances and in very small batches at home. However bread waste might be significantly reduced. Thus the net effects are difficult to quantify.

However, a 'best technology' scenario was also modelled using data from the most efficient plant among the 13 bakery sites studied by the Carbon Trust (2010), which operates at the medium-small scale to produce $c .39,000$ tonnes of bread per year. Thus the 'best technology' RDM scenario 2c assumed an energy intensity factor of $2.7 \mathrm{MJ} / \mathrm{kg}$ as primary energy demand per $\mathrm{kg}$ of product (see section 2.1 ).

There is significant potential for technology improvement with consequent energy efficiency improvement in medium and small bakeries, as shown by the scatter of performance data seen in the Carbon Trust study, and results for the 'best technology' scenario suggest that energy consumption may be potentially reduced in comparison to the current situation, assuming that best technologies and operational practices are used to manufacture up to $20 \%$ of bread at the medium-local RDM scale (see Figure 10 scenario $2 \mathrm{c}$ versus scenario 1 ).

Whether smaller plant can actually outperform large scale plants is uncertain as a result of this thought-experiment, which, it should be noted, does not examine the effects of transportation and scales up results from one medium-small highly efficient plant for the national level. However, there seems to be greater room for improvement, and further research in this area is recommended, as technological and operational aspects appear to have a stronger influence in determining energy efficiency than scale of production. 


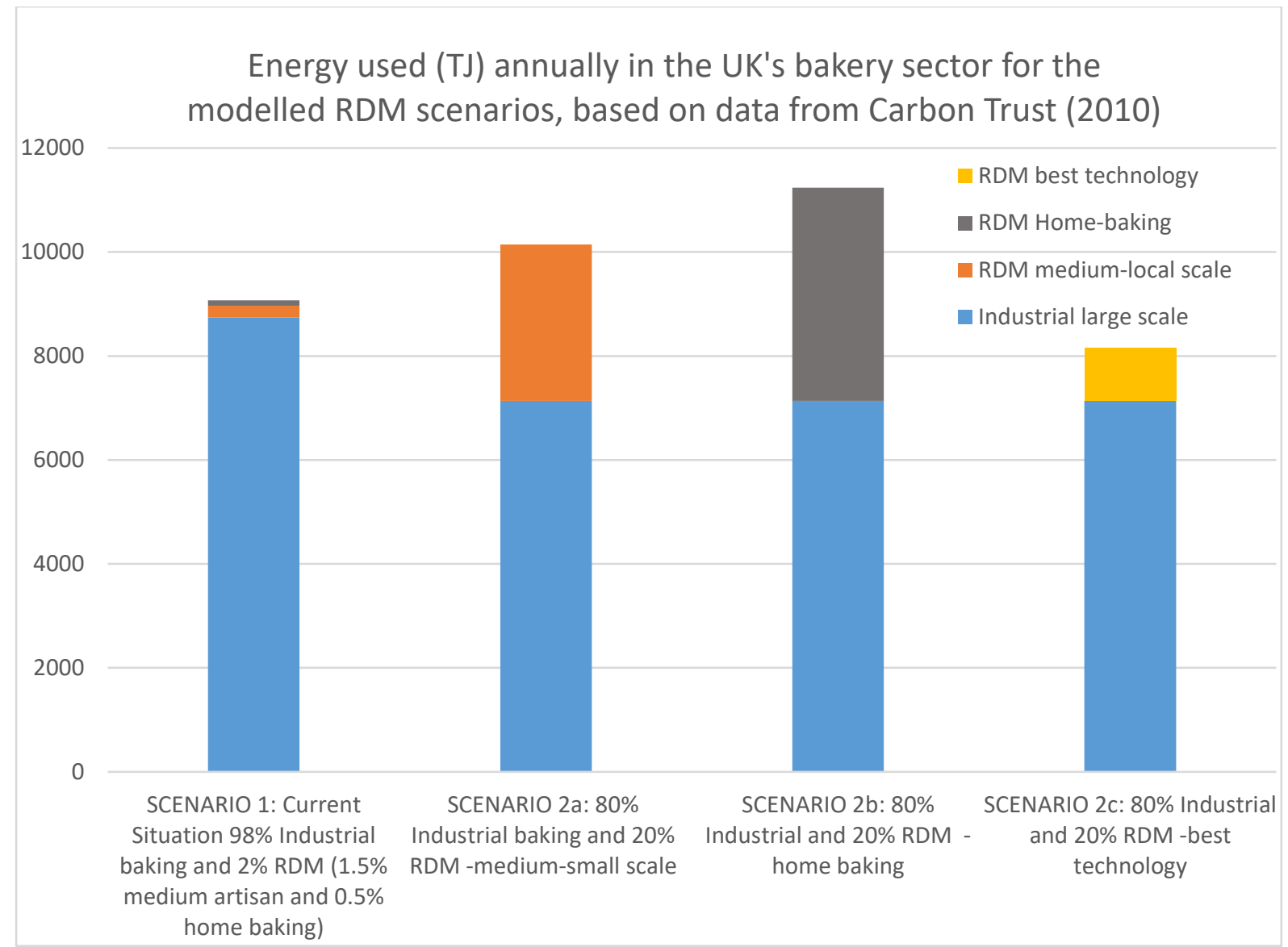

Figure 10: Energy consumed (TJ/year) in the UK's bakery sector for the current situation (Scenario 1) and hypothetical RDM scenarios (Scenarios $2 a, 2 b$ and $2 c$ ) representing a bigger share of locally manufactured bread

\subsection{Practical aspects of RDM and future research}

This study focused on the differences in energy demand for baking and transporting bread at different scales. However the social aspects related for example to local job creation, as well as the economic feasibility of all bread making scales and scenarios are very important and can be explored further. For example, energy consumption and emissions might get reduced, but labour costs could increase and affect the price and feasibility of manufacturing bread at one scale or another.

This study has identified other areas that would benefit from further research. For example estimates based on data and anecdotal evidence collected during site visits to mills and bakeries in Oxford and surroundings suggest that further energy and emissions savings are possible if renewable energy sources such as solar and hydro-electricity are developed and used at the local level. Based on one of the local mills visited it is estimated that up to $17 \%$ of their energy needs are covered using a local hydro-power generator on one of their sites. Similarly, the newly installed solar panels on a small combined bakery facility and shop near Oxford produced approximately $11 \%$ of their energy needs. Despite the physical constraints such as low river flows for hydroelectricity generation and limitations in roof-space for solar energy, there appears to be potential for these technologies to produce at least part of the energy needs of small scale mills and bakeries (López-Avilés and Leach, 2016). 
Large scale baking plants and mills may also benefit from investing in renewables. However the greater intensity of their operations suggests that they might face greater physical limitations such as available roof area. Thus, theoretical energy savings may be more difficult to realise in practice in large scale facilities.

Furthermore, opportunities for generating energy from waste in the bread supply chain (and from other food wastes) deserve further research. Given the proximity of RDM producers to consumers, the opportunities may be greater for useful recovery of food wastes for RDM than for centralised production.

There was no opportunity to assess the potential for energy integration and efficiencies across the local supply and production chains and with other sectors in this study. However it is noted from examples such as that of the Glockenbrot bakery in Bergkirchen, Germany, that waste energy from other sectors can be used in bread baking. In this German example, three waste incineration lines provide district heat and steam supply for a bakery, which through innovative energy efficiency processes has reduced its energy demand to $70 \%$ of conventional production systems. The Bergkirchen bakery reportedly emits $46 \%$ less GHGs than traditional bakeries ${ }^{19}$.

Another interesting aspect to study further is the geographical distribution of air pollution and the health implications of moving manufacturing activities closer to urban areas and the potential for using electric vehicles in urban settings.

\section{Conclusions}

Down-scaling and decentralising manufacturing may result in greater energy and water consumption and higher prices due to the loss of economies of scale and logistical problems (e.g. limited space to implement efficiencies or install latest technology in manufacturing processes at the local level, especially by small scale manufacturers). This paper demonstrates that with current technology and current user practices, increasing the share of local bread manufacturing would be likely to increase energy use and environmental impacts.

However, there are multiple opportunities to reduce energy usage and GHG emissions associated with redistributed manufacturing, and taken together, these could lead to overall lower energy use and emissions than with the current centralised systems. This paper explored the implications and potential opportunities of downscaling bread production in the UK, taking Oxford as a case study.

Based on the modelled energy usage and emissions of various bread supply chain configurations for the large, medium and small scales, the following conclusions are drawn:

- Modelled energy system configurations for both centralised industrial bread production and re-distributed bread manufacturing and transportation indicate that energy usage and greenhouse gas emissions can increase as a result of localising bread manufacturing.

- However the study has demonstrated that energy use and emissions associated with the transport stages of the bread supply chain tend to dominate. As such RDM has potential to reduce overall energy consumption and emissions as a result of:

\footnotetext{
${ }^{19}$ http://www.proplanet-label.com/produkte/rewe/brot-und-backwaren.html) and http://www.gfaonline.com/index.php
} 
1. transporting bread from local plants to retailers instead of delivering bread long distances from centralised industrial bakery plants,

2. reducing car usage if more consumers buy in local bakeries, and

3. using low carbon vehicles to distribute bread and flour at the medium and small scales.

- The energy consumption in baking bread depends to a large degree on technological and operational practices rather than production scale and location. The prospects for technological improvement at the medium and smaller scales may well be greater than for those at large scale, including the potential for implementing renewable energy supplies.

- This study suggests that there are some additional ways in which RDM of bread may offer benefits, especially, there is potential for energy recovery from postconsumer food waste and opportunities for energy integration within and between industries/ sectors, but these aspects were not studied in detail.

it is noted that the case of Oxford might be somewhat special and could affect the data and analysis as this is a city dominated by a strong contingency of students who cycle and walk, and do not have a private car. Oxford's local government policies on sustainability and the implementation of infrastructure such as cycling and pedestrian routes have also strongly encouraged active commuting which may translate into some bias on the data for the case study. Moreover, it is acknowledged that Oxford is an affluent location with an above-average per capita income and a growing interest in local scale shops and locally produced goods, as well as a thriving business sector around crafted foods. Thus, there is also a large amount of research work around the food sector carried out in Oxford, and this guided the selection of the city as a case study.

However, and despite these special characteristics, Oxford can be seen as a leader in trends that are expected to extend more widely in the UK, where numerous towns and cities are shifting away from motorised transport, and switching from private cars to public transport, driven by concerns over climate change, traffic congestion, local air quality and health. Therefore, the conclusions of this research are relevant to a number of other towns and cities in the south of England and elsewhere, which have similar socio-economic characteristics, e.g. Exeter, Bristol, Brighton, London, Bath, Reading, and it is considered that this research can be extended to these cities and other areas, especially if similar policies are put in place.

This research has implications for policy on the promotion of localising food manufacturing and retail, which have to go in tandem with ongoing policies and incentives for sustainable transport, including electric vehicles, improved public transport, cycling and walking. The results here presented help to move towards step change or gradual transition policies encouraging redistributed food manufacturing in parallel with implementing the most energy efficient technologies and practices in the bread processing sector. The consumer phase is important in the overall energy and emissions of the supply-chain of bread, and the initial research presented here suggests that even a small reduction in the number of shopping trips using private cars can achieve significant improvements in energy use and emissions, and that consumers shopping habits can be changed by having more local shops.

The potential for energy and environmental improvement through redistributing manufacture has been signposted here, but further work is needed to explore in detail, to better understand the technological and user behaviour changes required. It will also be important to link such further work to wider questions about the nature and liveability 
of cities: decentralising production brings changes to employment patterns; shopping on foot or by bike helps reclaim neighbourhoods from the car; and ultimately these effects impact on future urban development. These are topics well beyond the scope of the current paper, but the analysis here lends support from the techno-economic perspective on redistributed manufacturing to more extensive socio-economic study. 


\section{Acknowledgements and funding sources}

The wider set of Local Nexus Network project partners contributed to the development of the RDM scenarios and the underlying approach to this study, and their contributions are gratefully acknowledged.

This work was supported by the UK Engineering \& Physical Sciences Research Council (EPSRC) project 'Building sustainable local nexuses of food, energy and water: from smart engineering to shared prosperity (The Local Nexus Network) (EP/M017753/1). 


\section{References}

Andersson, K. and T. Ohlsson (1999) 'Life cycle assessment of bread produced on different scales'. The International Journal of Life Cycle Assessment. 4(1): p. 25-40.

Barling D., Sharpe, R. and Lang, T. (2011) 'Traceability and ethical concerns in the UK wheat-bread chain: from food safety to provenance to transparency', International Journal of Agricultural Sustainability, http://www.tandfonline.com/loi/tags20 Published online: 08 Jun 2011.

Barr, S. and Prillwitz, J. (2014). A smarter choice? Exploring the behaviour change agenda for environmentally sustainable mobility. Environment and Planning C: Government \& Policy, 32(1), 1-19. Beech, G.A. (1980) 'Energy use in bread baking'. Journal of the Science of Food and Agriculture. 31(3): p. 289-298, revised and published on-line in 2006

Beddington J. (2009) 'Food, energy, water and the climate: a perfect storm of global events?' Conference presentation given to the Sustainable Development UK Annual Conference, QEII Conference Centre, London, 19 March 2009.

http://www.bis.gov.uk/assets/goscience/docs/p/perfect-storm-paper.pdf (accessed 11 May 2015).

Braschkat, J., Patyk, A., Quirin, M., \& Reinhardt, G. A. (2004) 'Life cycle assessment of bread production - a comparison of eight different Scenarios'. In Halberg, N. (ed.) 'Life Cycle Assessment' DIAS report, Danish Institute of Agricultural Sciences, Department of Agro-ecology, 2004.

Carbon Trust (2010) 'Industrial Energy Efficiency Accelerator - Guide to the industrial bakery sector', known as Industrial bakery report CTG034 prepared by the Carbon Trust from the technical work completed by SKM Enviros Ltd with assistance from the Food and Drink Association, pp. 65.

Carbon Trust (2015a) (study by Ashcroft) 'Improving the efficiency of bakery ovens case study', report CTS402. http://www.carbontrust.com/media/642185/cts402improving-efficiency-of-bakery-ovens.pdf

Carbon Trust (2015b) reporting on 'Taking the hot air out of baking bread', 2 April 2015, see http://www.carbontrust.com/about-us/press/2015/04/carbon-trust-takes-thehot-air-out-of-baking-bread

Carlsson-Kanyama, A. and Faist, M. (2000) 'Energy Use in the Food Sector: a data survey', Environmental Strategies Research Group, Stockholm University, Sweden and Department of Civil and Environmental Engineering, Swiss Federal Institute of Technology, Switzerland.

Chapagain, A.K., Hoekstra, A. Y. and Savenije, H.H.G. (2006), 'Water saving through international trade of agricultural products', Hydrology and Earth System Sciences,2006, 10(3), 455-468.

Charles, R., Jolliet, O., Gaillard, G. and Pellet, D. (2006) 'Environmental analysis of intensity level in wheat crop production using life cycle assessment', Agriculture, Ecosystems and Environment, 113, pp. 216-225.

Coley, D., Howard, M., and Winter, M. (2009) 'Local food, food miles and carbon emissions: A comparison of farm shop and mass distribution approaches', Food Policy, 
Vol 34, Issue 2, April 2009, Pages 150-155.

https://www.sciencedirect.com/science/article/abs/pii/S0306919208000997

DEFRA (2015) 'UK-household purchases F.R.A.', Department for Environment Food and Rural Affairs, see

https://www.gov.uk/government/uploads/system/uploads/attachment data/file/5977 12/familyfood-2015-webtables-09mar17.ods

EPA (2008a) 'Average Annual Emissions and Fuel Consumption for Gasoline-Fueled Passenger Cars and Light Trucks', U.S. Environmental Protection Agency.

EPA (2008b) 'Average In-Use Emissions from Heavy-Duty Trucks', U.S. Environmental Protection Agency.

EPSRC and ESRC (2013) 'Re-Distributed Manufacturing Workshop Report', 7-8 November 2013, see https://www.epsrc.ac.uk/newsevents/pubs/re-distributed-manufacturingworkshop-report

Espinoza-Orias, N., Stichnothe, H. and Azapagic, A. (2011) 'The carbon footprint of bread', International Journal of Life Cycle Assessment, 16:351-365. DOI 10.1007/s11367011-0271-0.

Federation of Bakers (2015) 'About The Bread Industry', cited 2016 May; Available from: http://www.bakersfederation.org.uk/the-bread-industry/about-the-bread-industry/

Foresight (2013) 'The Future of Manufacturing: A new era of opportunity and challenge for the UK: Summary Report', The Government Office for Science, London, see https://www.gov.uk/government/uploads/system/uploads/attachment data/file/2559 23/13-810-future-manufacturing-summary-report

Galli, F., Bartolini, F., Brunori, G., Colombo, L., Gava, O., Grando, S. and Marescotti, A. (2015) 'Sustainability assessment of food supply chains: an application to local and global bread in Italy', Agricultural and Food Economics, 3:21, DOI 10.1186/s40100015-0039-0.

Greenhouse Gas Protocol, Calculating $\mathrm{CO}_{2}$ Emissions from Mobile Sources, see https://www.aircanada.com/content/dam/aircanada/portal/documents/PDF/agents/en Ldocuments/co2-mobile.pdf

Guy, C. (2009) 'Sustainable transport choices in Consumer Shopping: a review of the UK evidence'. International Journal of Consumer Studies, vol. 33(6): pp. 652-658. http://onlinelibrary.wiley.com/doi/10.1111/j.1470-6431.2009.00818.x/pdf

HM Government (2009) 'The UK Low Carbon Transition Plan. National strategy for climate and energy'. Presented to Parliament pursuant to Sections 12 and 14 of the Climate Change Act 2008. Amended 20th July 2009 from the version laid before Parliament on 15th July 2009, published by TSO (The Stationery Office) pp. 223

Hoehner, C. M., Ramirez, L. K. B., Elliott, M. B., Handy, S. L. and Brownson, R. C. (2005). Perceived and objective environmental measures and physical activity among urban adults. American journal of preventive medicine, 28(2), 105- 116.

Kantar World Panel (2015a) 'The great grocery revolution - What is really happening to Britain's supermarkets?' at www.kantarworldpanel.com/dwl.php?sn=news downloads\&id $=733$ 
Kantar World Panel (2015b) 'NAVIGATING THE CUSTOMER JOURNEY. Don't forget the category and think small as well as big' in https://www.kantarworldpanel.com/global/Publications

Le-bail, A., Dessev, T., Jury, V., Zuniga, R., Park, T., and Pitroff, M. (2010) 'Energy demand for selected bread making processes: Conventional versus part baked frozen technologies', Journal of Food Engineering 96 (2010) 510-519.

López-Avilés, A. and Leach, M., (2016) 'Local Nexus Network for Re-Distributed Manufacturing: Energy Feasibility Study. Final Report July 2016', EPSRC and ESRCfunded project output published online: http://localnexus.org/wpcontent/uploads/2015/04/LNN-Energy-Feasibility-Report Final July-2016.pdf

Manfredi, M. and Vignali, G. (2014) 'Life cycle assessment of a packaged tomato puree: a comparison of environmental impacts produced by different life cycle phases', Journal of Cleaner Production, Vol 73 (2014), p. 275-284.

Masanet, E., P. Therkelsen, and E. Worrell (2012) 'Energy Efficiency Improvement and Cost Saving Opportunities for the Baking Industry - An ENERGY STAR® Guide for Plant and Energy Managers'. Ernest Orlando Lawrence Berkeley National Laboratory.

McKinnon, A. and Piecyk, M. (2010) 'Measuring and managing $\mathrm{CO}_{2}$ emissions'. Edinburgh: European Chemical Industry Council.

McKinsey \& Company (2009) 'Charting Our Water Future: Economic frameworks to inform decision-making', 2030 Water Resources Group, p. 185.

Nordh, H., Vistad, O. I., Skår, M., Wold, L. C. and Bærum, K. M. (2017). Walking as urban outdoor recreation: Public health for everyone. Journal of Outdoor Recreation and Tourism.

OECD (2010) 'Sustainable Management of Water Resources in Agriculture', published by the Organisation for Economic Co-operation and Development (OECD), p. 122.

Oxford City Council (2011) Households | Oxford City Council. 2011 [cited 2016; Available from: https://www.oxford.gov.uk/info/20131/population/496/households.

Oxfordshire County Council (2016) 'Active \& Healthy Travel Strategy', Volume 4 of Local Transport Plan 2015-2031: Connecting Oxfordshire, updated and adopted in 2016, Vol 4, pp. 19.

Paton J. B. (2013) 'Energy utilisation in commercial bread baking', PhD thesis. http://etheses.whiterose.ac.uk/4666/1/thesis joe paton.pdf

Raaschou-Nielsen, O., et al., (2013) 'Air pollution and lung cancer incidence in 17 European cohorts: prospective analyses from the European Study of Cohorts for Air Pollution Effects (ESCAPE)'. The Lancet Oncology. Vol. 14(9): p. 813-822.

Ringler C., Bhaduri, A. and Lawford, R. (2013) 'The nexus across water, energy, land and food (WELF): potential for improved resource use efficiency?', Current Opinion in Environmental Sustainability 2013, 5:617-624.

Tassou, S.A., Kolokotroni, M., Gowreesunker, B., Stojceska, V., Azapagic, A., Fryer, P. and Bakalis, S. (2014) 'Energy demand and reduction opportunities in the UK food chain'. Proceedings of the Institution of Civil Engineers, Energy Volume 167 Issue EN3, August 2014, Pages 162-170 http://dx.doi.org/10.1680/ener.14.000 
Thomsson, O. (1999) 'Systems Analysis of Small-Scale Systems for Food Supply and Organic Waste Management', in Department of Agricultural Engineering SLU, Uppsala, Sweden.

Verplanken, B., Walker, I., Davis, A. and Jurasek, M. (2008). Context change and travel mode choice: Combining the habit discontinuity and self-activation hypotheses. Journal of Environmental Psychology, 28(2), 121-127.

WEF -World Economic Forum (2011) 'Water Security: the Water-Food-Energy-Climate Nexus' Chapter 2: Energy. Inland Press, the Centre for Resource Economics, Waughray D. (Ed).

Whittle, C., Haggar, P., Whitmarsh, L., Morgan, P. Xenias, D. and Parkhurst, G. (2019) 'Decision-Making in the UK Transport System. Future of Mobility: Evidence Review', Foresight, Government Office for Science, pp. 86.

Williams, A.G., Audsley, E. and Sandars, D.L. (2006) 'Determining the environmental burdens and resource use in the production of agricultural and horticultural commodities'. Main Report and Executive Summary, Defra Research Project IS0205. Bedford: Cranfield University and Defra. Available on www.silsoe.cranfield.ac.uk and www.defra.gov.uk.

WRAP (2013) 'Hotspots, opportunities \& initiatives: Bread \& rolls', May 2013, see http://www.wrap.org.uk/sites/files/wrap/Bread\%20\&\%20rolls\%20v1.pdf

WRAP (2014) 'Household food and drink waste: a product focus - Final Report' at http://www.wrap.org.uk/sites/files/wrap/Product-focused\%20report\%20v5 3.pdf 


\section{Appendix A}

Table A.1 Energy requirements ( $\mathrm{kWh} / \mathrm{kg}$ of bread) for various manufacturing processes and scales (including industrial and domestic flour milling) as reported in the literature

\begin{tabular}{|c|c|c|c|}
\hline Scale & $\begin{array}{l}\text { Process, and bakery technology } \\
\text { type }\end{array}$ & $\begin{array}{l}\text { Energy use } \\
\mathrm{kWh} / \mathrm{Kg} \text { of } \\
\text { bread }\end{array}$ & Source \\
\hline \multirow{3}{*}{ 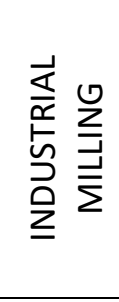 } & $\begin{array}{l}\text { Wheat milling (kWh/ 800gr white- } \\
\text { bread loaf) }\end{array}$ & 0.07 & $\begin{array}{l}\text { Espinoza-Orias et al., (2011) reported as } \\
0.059 \mathrm{kWh} \text { per } 800 \mathrm{~g} \text { white bread-loaf }\end{array}$ \\
\hline & $\begin{array}{l}\text { Wheat milling (kWh/800gr brown- } \\
\text { bread loaf) }\end{array}$ & 0.06 & $\begin{array}{l}\text { Espinoza-Orias et al., (2011) reported as } \\
0.048 \mathrm{kWh} \text { per } 800 \mathrm{~g} \text { white bread-loaf }\end{array}$ \\
\hline & $\begin{array}{l}\text { Wheat milling (kWh/800gr all- } \\
\text { bread type loaf) }\end{array}$ & 0.13 & $\begin{array}{l}\text { Espinoza-Orias et al., (2011) reported as } \\
0.107 \mathrm{kWh} \text { per } 800 \mathrm{~g} \text { white bread-loaf }\end{array}$ \\
\hline \multirow{7}{*}{ 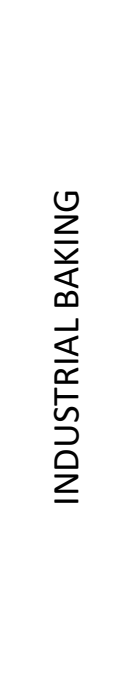 } & $\begin{array}{l}\text { Large bakery facility } 800 \mathrm{gr} \text { white- } \\
\text { bread loaf }\end{array}$ & 0.75 & $\begin{array}{l}\text { Espinoza-Orias et al., (2011) reported as } \\
0.6 \mathrm{kWh} \text { per } 800 \mathrm{~g} \text { white bread-loaf }\end{array}$ \\
\hline & Large plant facility & 0.80 & $\begin{array}{l}\text { Calculated based on data from Carbon } \\
\text { Trust (2010) }\end{array}$ \\
\hline & Large plant bakery & 1.11 & $\begin{array}{l}\text { Le-bail et al., (2010) reported as } 4 \\
\mathrm{MJ} / \mathrm{Kg} \text { of bread }\end{array}$ \\
\hline & $\begin{array}{l}\text { Large plant bakery (inc. wheat } \\
\text { growing, flour milling, baking \& retail) }\end{array}$ & 4.11 & $\begin{array}{l}\text { Beech (1980) reported as } 14.8 \mathrm{MJ} / \mathrm{Kg} \text { of } \\
\text { bread }\end{array}$ \\
\hline & $\begin{array}{l}\text { Large plant bakery (flour arrival at } \\
\text { bakery to bread arrival at retail outlet) }\end{array}$ & 1.94 & $\begin{array}{l}\text { Beech (1980) reported as } 6.99 \mathrm{MJ} / \mathrm{Kg} \text { of } \\
\text { bread }\end{array}$ \\
\hline & Large plant bakery & 1.31 & $\begin{array}{l}\text { Braschkat et al., (2004) reported as } 4.7 \\
\mathrm{MJ} / \mathrm{Kg} \text { of bread }\end{array}$ \\
\hline & Large plant bakery (organic wheat) & 0.97 & $\begin{array}{l}\text { Braschkat et al., (2004) reported as } 3.5 \\
\mathrm{MJ} / \mathrm{Kg} \text { of bread }\end{array}$ \\
\hline \multirow{3}{*}{ 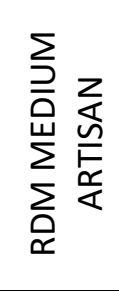 } & $\begin{array}{l}\text { Medium bakery facility (part- } \\
\text { frozen/part-baked bread) }\end{array}$ & 2.44 & $\begin{array}{l}\text { Le-bail et al., (2010) reported as } 8.8 \\
\mathrm{MJ} / \mathrm{Kg} \text { of bread }\end{array}$ \\
\hline & Artisan bakery facility & 1.67 & $\begin{array}{l}\text { Braschkat et al., (2004) reported as } 6 \\
\mathrm{MJ} / \mathrm{Kg} \text { of bread }\end{array}$ \\
\hline & $\begin{array}{l}\text { Artisan bakery facility (organic } \\
\text { wheat) }\end{array}$ & 1.44 & $\begin{array}{l}\text { Braschkat et al., (2004) reported as } 5.2 \\
\mathrm{MJ} / \mathrm{Kg} \text { of bread }\end{array}$ \\
\hline \multirow{6}{*}{ 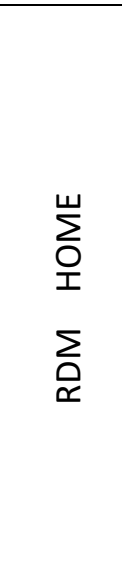 } & Home baking gas oven & 2.82 & $\begin{array}{l}\text { Beech (1980) average } 10.15 \mathrm{MJ} / \mathrm{Kg} \text { of } \\
\text { bread taken from range } 4.24 \text { to } 16.05\end{array}$ \\
\hline & Home baking electric oven & 9.11 & $\begin{array}{l}\text { Beech (1980) average } 32.8 \mathrm{MJ} / \mathrm{Kg} \text { of } \\
\text { bread taken from range } 10.84 \text { to } 54.76\end{array}$ \\
\hline & Home bread maker, domestic mill & 2.39 & $\begin{array}{l}\text { Braschkat et al., (2004) reported as } 8.6 \\
\mathrm{MJ} / \mathrm{Kg} \text { of bread }\end{array}$ \\
\hline & Home bread maker, industrial mill & 2.28 & $\begin{array}{l}\text { Braschkat et al., (2004) reported as } 8.2 \\
\mathrm{MJ} / \mathrm{Kg} \text { of bread }\end{array}$ \\
\hline & $\begin{array}{l}\text { Home bread maker, domestic mill } \\
\text { (organic wheat) }\end{array}$ & 2.17 & $\begin{array}{l}\text { Braschkat et al., (2004) reported as } 7.8 \\
\mathrm{MJ} / \mathrm{Kg} \text { of bread }\end{array}$ \\
\hline & $\begin{array}{l}\text { Home bread maker, industrial mill } \\
\text { (organic wheat) }\end{array}$ & 2.03 & $\begin{array}{l}\text { Braschkat et al., (2004) reported as } 7.3 \\
\mathrm{MJ} / \mathrm{Kg} \text { of bread }\end{array}$ \\
\hline
\end{tabular}




\section{Appendix B}

DATA FOR FIGURE 3

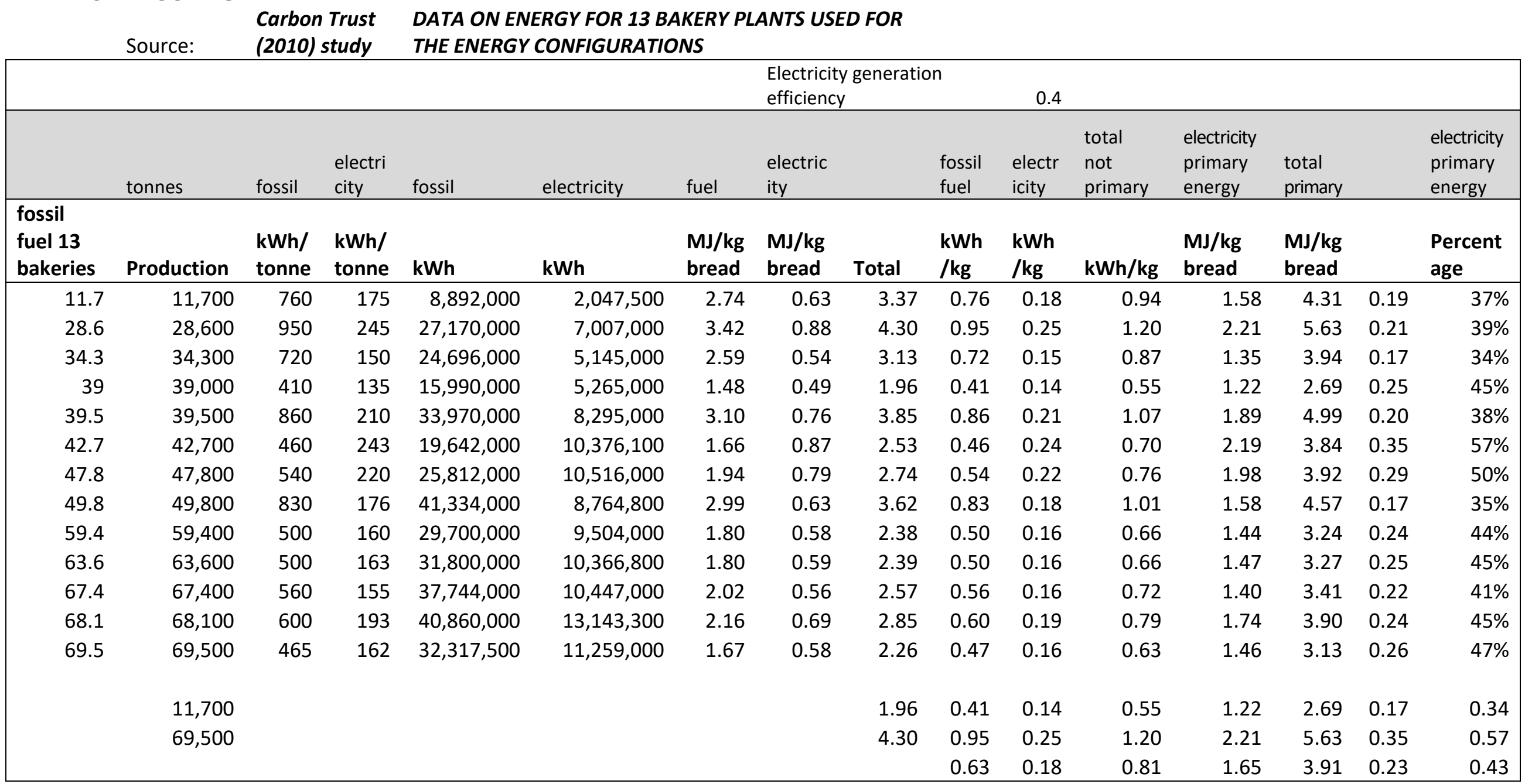




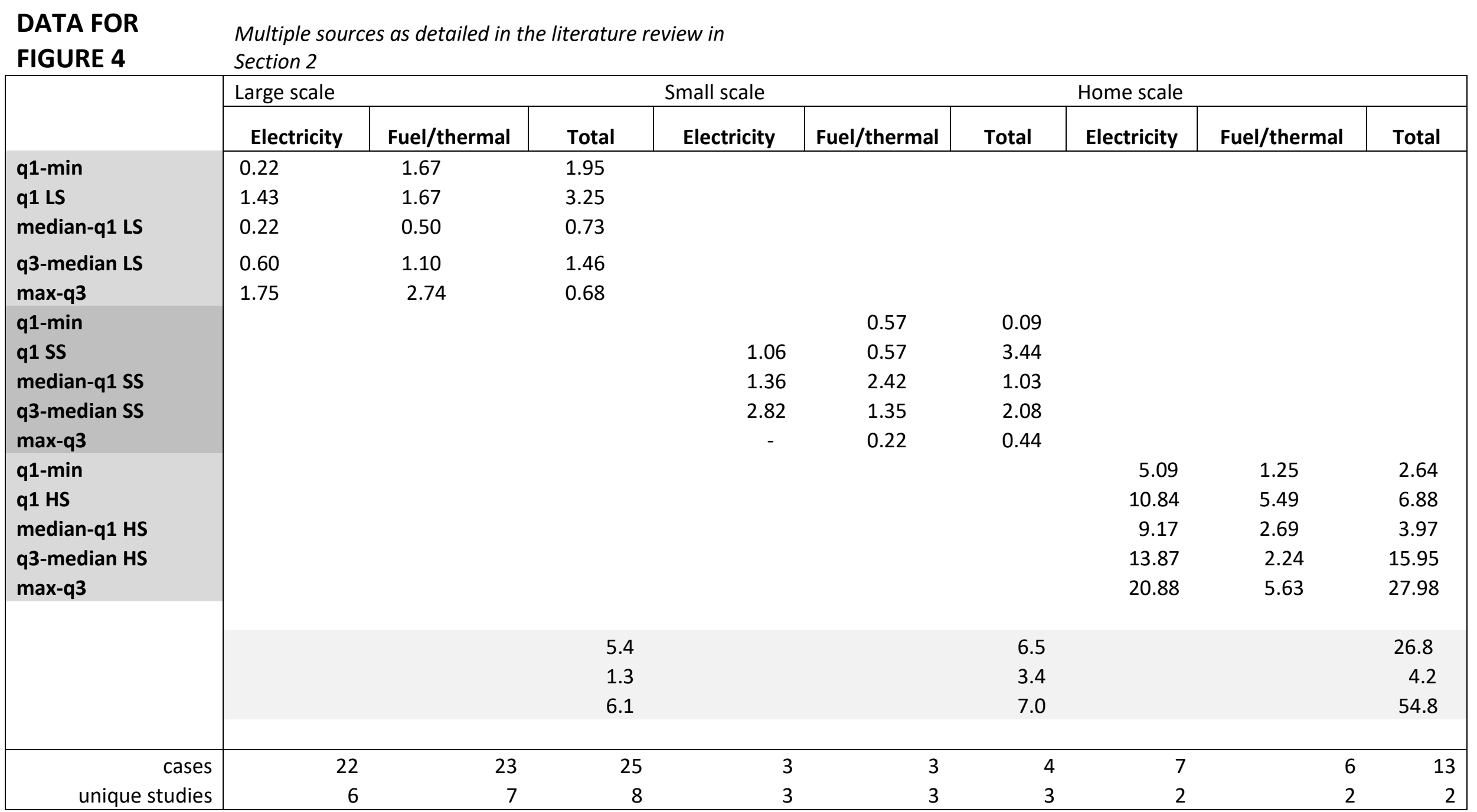


DATA FOR FIGURE 5

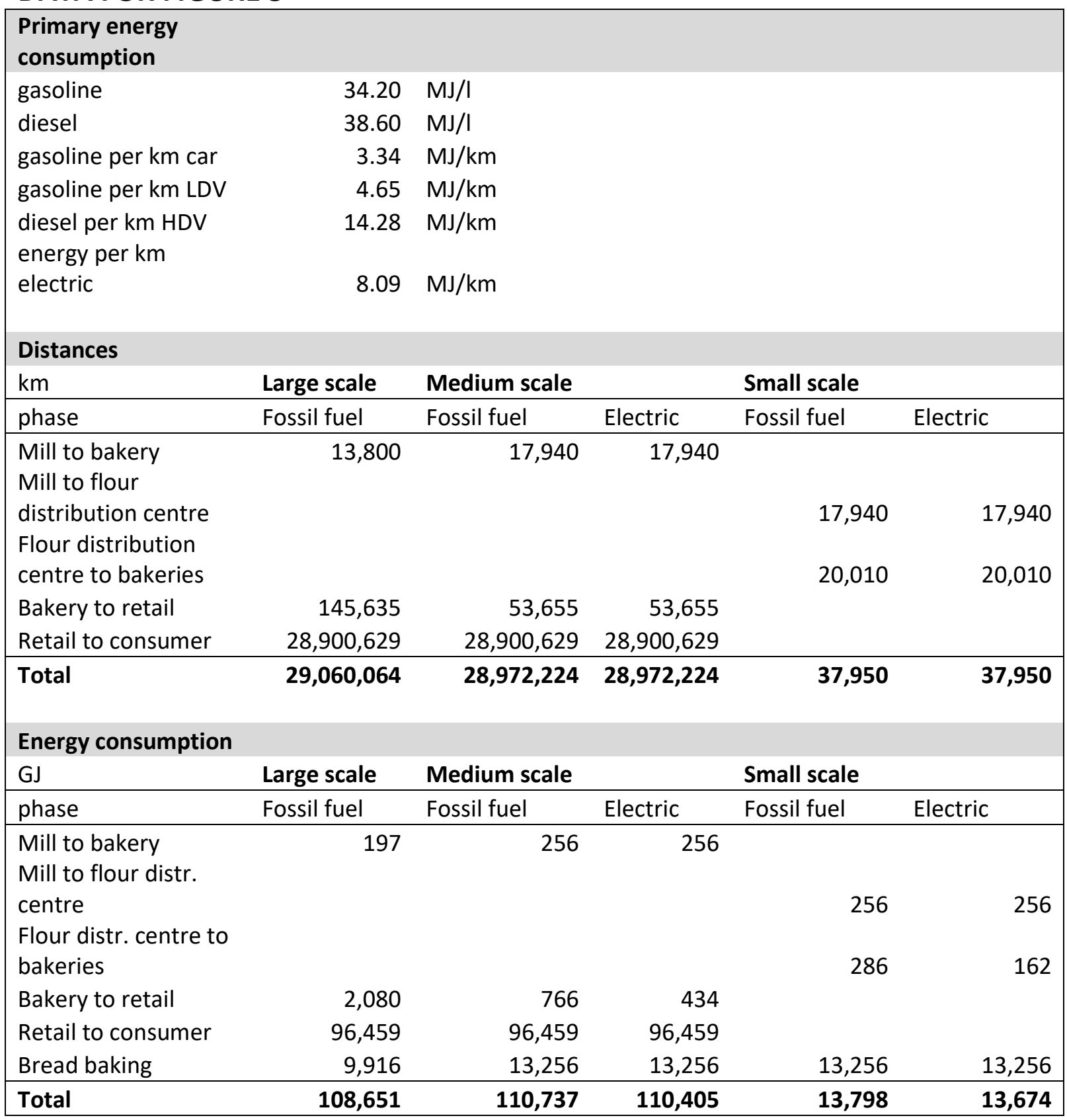


DATA FOR

\section{FIGURE 6}

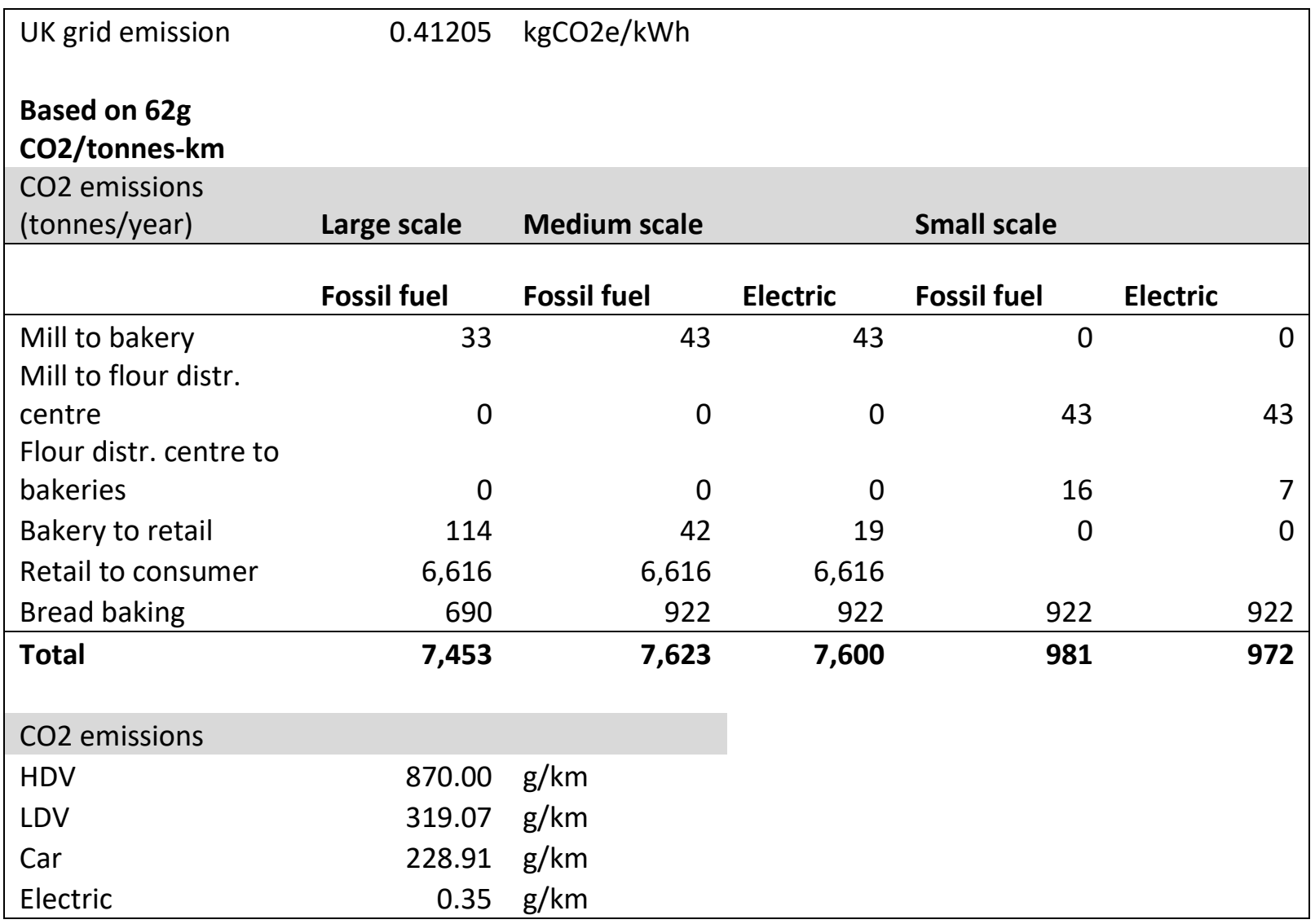

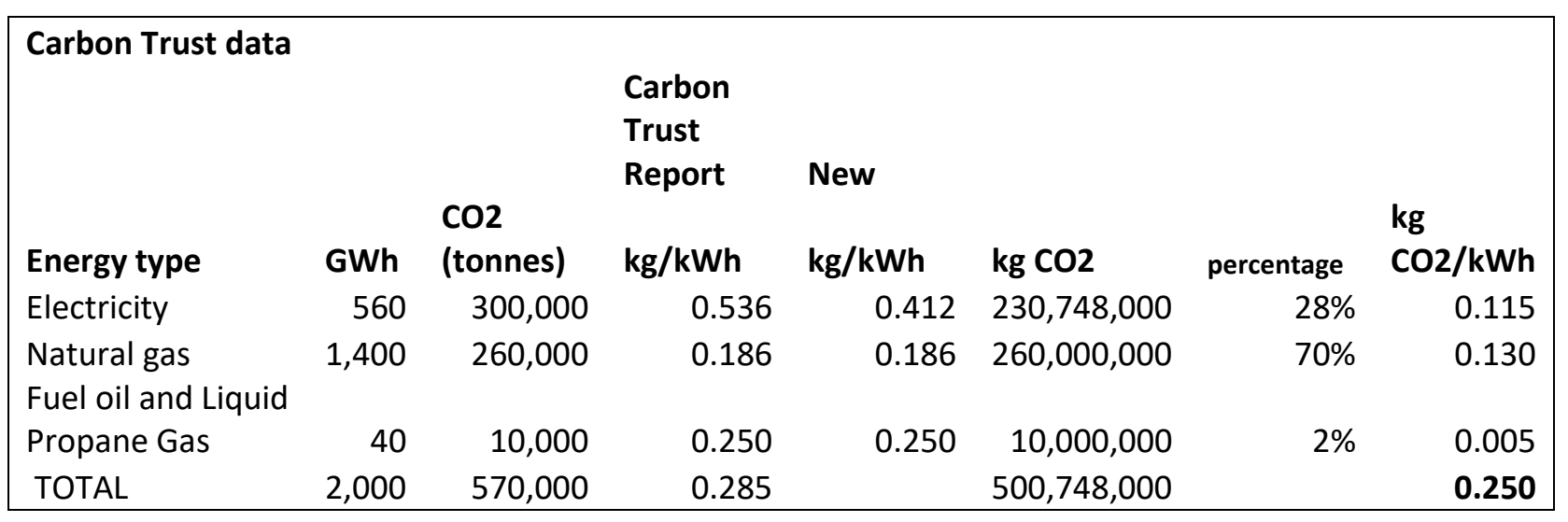


DATA FOR

\section{FIGURE 7}

\begin{tabular}{|c|c|c|c|}
\hline \multicolumn{4}{|c|}{ Distances times emissions/km } \\
\hline & & & electric \\
\hline \multirow[t]{6}{*}{ Large scale } & VOC & 0.04 & 18.57 \\
\hline & $\mathrm{THC}$ & 0.04 & 19.34 \\
\hline & $\mathrm{CO}$ & 0.23 & 168.81 \\
\hline & NOx & 0.85 & 12.44 \\
\hline & PM10 & 0.02 & 0.08 \\
\hline & PM2.5 & 0.02 & 0.07 \\
\hline \multirow[t]{6}{*}{ Medium scale } & VOC & 0.02 & 18.57 \\
\hline & $\mathrm{THC}$ & 0.02 & 19.34 \\
\hline & $\mathrm{CO}$ & 0.10 & 168.81 \\
\hline & NOx & 0.38 & 12.44 \\
\hline & PM10 & 0.01 & 0.08 \\
\hline & PM2.5 & 0.01 & 0.07 \\
\hline \multirow[t]{6}{*}{$\begin{array}{l}\text { Medium scale } \\
\text { electric }\end{array}$} & VOC & 0.00 & 18.57 \\
\hline & THC & 0.01 & 19.34 \\
\hline & $\mathrm{CO}$ & 0.03 & 168.81 \\
\hline & NOx & 0.10 & 12.44 \\
\hline & PM10 & 0.00 & 0.08 \\
\hline & PM2.5 & 0.00 & 0.07 \\
\hline \multirow[t]{6}{*}{ Small scale } & VOC & 0.01 & 0 \\
\hline & $\mathrm{THC}$ & 0.01 & 0 \\
\hline & $\mathrm{CO}$ & 0.05 & 0 \\
\hline & NOx & 0.20 & 0 \\
\hline & PM10 & 0.00 & 0 \\
\hline & PM2.5 & 0.00 & 0 \\
\hline \multirow[t]{6}{*}{ Small scale electric } & VOC & 0.00 & 0 \\
\hline & $\mathrm{THC}$ & 0.01 & 0 \\
\hline & $\mathrm{CO}$ & 0.03 & 0 \\
\hline & NOx & 0.10 & 0 \\
\hline & PM10 & 0.00 & 0 \\
\hline & PM2.5 & 0.00 & 0 \\
\hline
\end{tabular}




\section{DATA FOR}

\section{FIGURE 8}

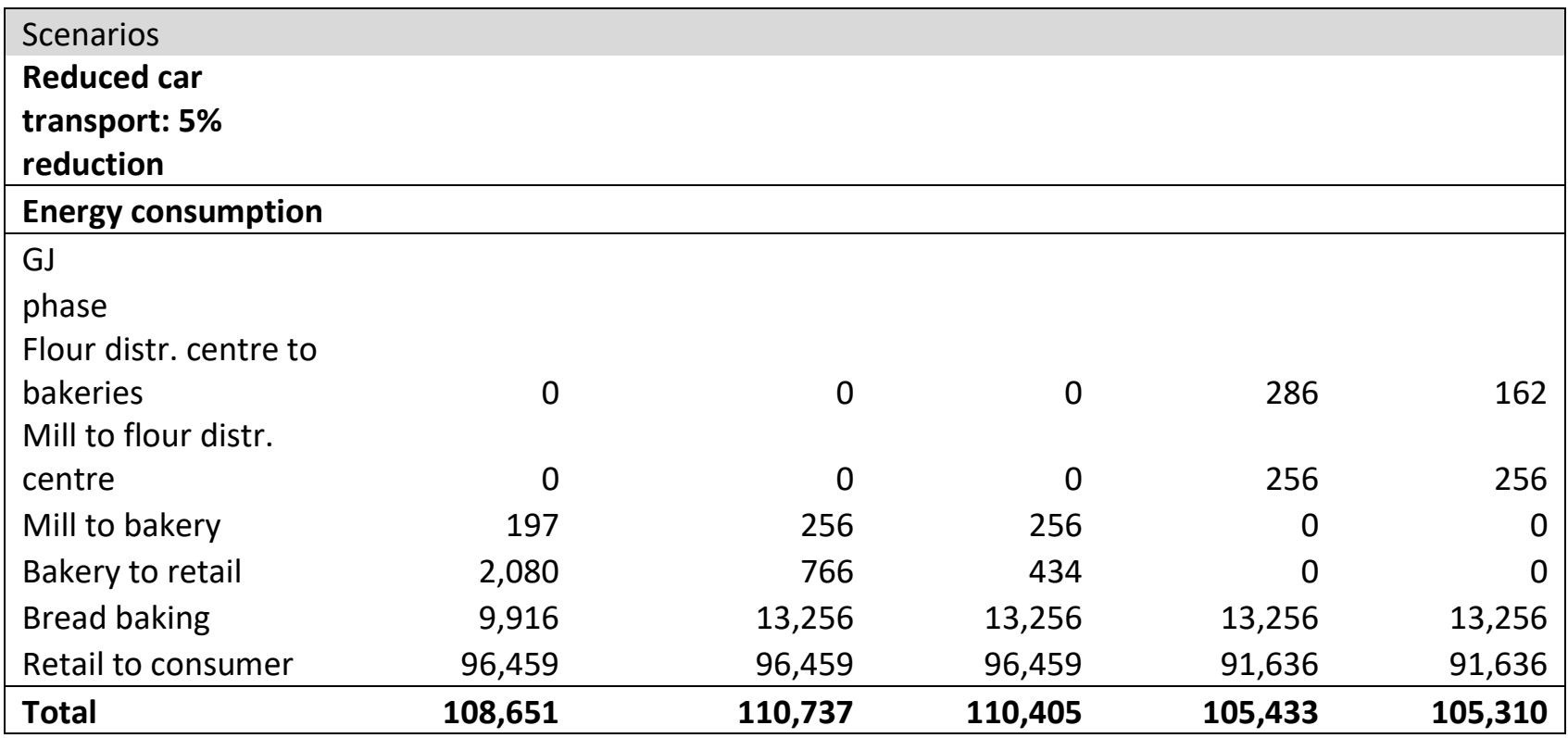

\section{DATA FOR}

\section{FIGURE 10}

\begin{tabular}{|c|c|c|c|c|c|}
\hline \multicolumn{2}{|c|}{$\begin{array}{l}\text { Data for final energy RDM scenarios } \\
\text { graph }\end{array}$} & Energy Use (TJ) & $\begin{array}{l}\text { Energy Use } \\
\text { (TJ) }\end{array}$ & $\begin{array}{l}\text { Energy Use } \\
\text { (TJ) }\end{array}$ & $\begin{array}{l}\text { Energy Use } \\
\text { (TJ) }\end{array}$ \\
\hline SOURCE DATA & Scale & $\begin{array}{l}\text { SCENARIO 1: } \\
\text { Current Situation } \\
98 \% \text { Industrial } \\
\text { baking and } 2 \% \\
\text { RDM }(1.5 \% \\
\text { medium artisan } \\
\text { and } 0.5 \% \text { home } \\
\text { baking) }\end{array}$ & $\begin{array}{l}\text { SCENARIO } \\
2 \text { a: } 80 \% \\
\text { Industrial } \\
\text { baking and } \\
20 \% \text { RDM - } \\
\text { medium- } \\
\text { small scale }\end{array}$ & $\begin{array}{l}\text { SCENARIO } \\
2 \mathrm{~b}: \mathbf{8 0} \% \\
\text { Industrial } \\
\text { and } 20 \% \\
\text { RDM -home } \\
\text { baking }\end{array}$ & $\begin{array}{l}\text { SCENARIO } \\
\text { 2c: } 80 \% \\
\text { Industrial } \\
\text { and } 20 \% \\
\text { RDM -best } \\
\text { technology }\end{array}$ \\
\hline $\begin{array}{l}\text { Average misc } \\
\text { sources (see }\end{array}$ & Industrial & & & & \\
\hline Appendix A) & $\begin{array}{l}\text { large scale } \\
\text { RDM } \\
\text { medium- }\end{array}$ & 8,744 & 7,138 & 7,138 & 7,138 \\
\hline Braschkat et al, 2004 & $\begin{array}{l}\text { local scale } \\
\text { RDM Home- }\end{array}$ & 225 & 3,006 & 0 & 0 \\
\hline Braschkat et al, 2004 & baking & 103 & 0 & 4,100 & 0 \\
\hline Carbon Trust 2010 & technology & 0 & 0 & 0 & 1,012 \\
\hline
\end{tabular}

$1 \mathrm{GWh}=3.6 \mathrm{TJ}$ 
The following assumptions were made to calculate power (GW) per year:

The industrial bakery sector produces $24 \mathrm{~h}$ per day 7 days a week, every week of the year.

It was assumed that the small scale sector produces approximately $1.5 \%$ of all UK bread produced during 5 h per day, 6 days a week, every week except for 2 weeks holiday

$0.5 \%$ of all UK bread is produced at the home level, in $3 \mathrm{~h}$ per day, 5 days per week, every week except 2 weeks of holidays in most households baking their own bread Note from the Carbon Trust (2010) study that the most efficient plant is not the one with largest production/largest scale. It produces c. 40000 tonnes per year and has fossil fuel intensity of $0.40 \mathrm{kWh} / \mathrm{kg}$ of product, and electricity use of $0.14 \mathrm{kWh} / \mathrm{kg}$ of product. Hence, if all bakery plants were to replicate this site and use similar technology and practices, the energy used by the UK's industrial bakery sector, and the associated CO2-e emissions, could be reduced significantly 


\section{Glossary}

$\mathrm{CO}_{2}$ Carbon Dioxide

CO Carbon Monoxide

EPSRC Engineering and Physical Sciences Research Council

ESRC Economic and Social Research Council

FEW Food-Energy-Water Nexus

GHG/s Green-House Gas/es

GJ Gigajoules

GWh Gigawatt hour

LNN Local Nexus Network

Mt Million tonnes

NOx Nitrogen Oxides

PM10 Particulate Matter $<=10$ microns

PM2.5 Particulate Matter $<=2.5$ microns

RDM Re-distributed manufacturing

TJ Terajoules

THC Total Hydrocarbons

VOC Volatile Organic Compounds 